\title{
LA GENERACIÓN DE DESTINOS BASADOS EN EXPERIENCIAS ENOTURÍSTICAS PARA EL SEGMENTO FAMILIAR
}

\author{
Ginesa Martínez del Vas* \\ Universidad Católica San Antonio de Murcia \\ https://orcid.org/0000-0002-2713-0636 \\ Miguel Ángel Beltrán Bueno* \\ Universidad Católica San Antonio de Murcia \\ https://orcid.org/0000-0002-3899-2397 \\ Laura Rubia Albert** \\ Patronato de Turismo de la Diputación de Tarragona \\ https://orcid.org/0000-0002-6797-9765
}

\section{RESUMEN}

El objetivo del presente artículo es descubrir los aspectos que más influyen en la configuración del producto familiar enoturístico e identificar las características que mejor definen el mismo. Para ello, se ha revisado la literatura al respecto y las páginas webs corporativas de diferentes empresas bodegueras y se han realizado entrevistas a responsables de algunas de dichas bodegas. Este estudio demuestra el potencial del segmento familiar en paralelo con el gran crecimiento de las experiencias diseñadas por las bodegas para el mismo, tratándose pues de una actividad económica emergente.

Palabras clave: Enoturismo; segmentación; turismo familiar; sector vitivinícola TurisTIC en familia.

Fecha de recepción: 24 de marzo de 2020.

Fecha de aceptación: 4 de septiembre de 2020.

* Facultad de Ciencias Jurídicas y de la Empresa Universidad Católica San Antonio de Murcia. Av. de los Jerónimos, 135.30107 Guadalupe MURCIA (España).E-mail: gmvas@ucam.edu, mabeltran@ucam.edu

** PECT TurisTIC en familia - Viña en familia - Patronato de Turismo de la Diputación de Tarragona. Passeig de Torroja, s/n. 43007 TARRAGONA (España).E-mail: 1rubia@dipta.cat 


\title{
Generating destinations based on wine tourism experiences for the family sector
}

\begin{abstract}
The aim of the present work is no other than bringing to light the most influential aspects with regards to "family eco-tourism product" setting, and also identifying what features best define it. On that respect, the winery companies concerned have been reviewing crucial aspects such as the whole narrative in use as well as their corporate web pages, for which purpose several winery managers have been interviewed.

The present study shows the family segment potential paralleled with an increase in experiences designed by winery companies for that purpose, thus unfolding and promoting an emerging economy.
\end{abstract}

Keyword: Enotourism; segmentation; family tourism; wine sector; TurisTIC en familia.

\section{INTRODUCCIÓN}

Las tendencias del mercado turístico se caracterizan por una demanda de productos y servicios cada vez más personalizados y novedosos, lo que permite a los turistas vivir una experiencia memorable (Aráujo, 2015). Por este motivo, las empresas deben definir bien sus públicos objetivos y estudiar sus deseos y expectativas con la finalidad de adaptar su oferta al máximo a sus requerimientos. En este marco el enoturismo es una actividad turística que se ha popularizado en las últimas décadas en España, observando cada vez más bodegas que se unen a la apuesta por esta nueva línea de negocio (Gilbert, 1992; ACEVIN, 2018a; Salvat, 2018). Además, los cambios en los patrones demográficos y la necesidad de combatir la despoblación en espacios rurales pueden ser incentivos relevantes para la apertura o adaptación de bodegas al turismo, a la vez que se han creado nuevas empresas de servicios complementarios en muchos territorios vinícolas. Para algunos autores (Serrano, 2015; Salvat, 2018), esta apuesta es especialmente atractiva para las empresas bodegueras debido al retorno económico de la propia actividad turística, y como estrategia de marketing, dando como resultado un incremento en las ventas de vino.

Aunque el enoturismo no esté tan consolidado y maduro como pueden ser otros productos turísticos, existen bastantes publicaciones en el ámbito académico que analizan el origen y desarrollo del enoturismo, así como la evolución de la demanda y la oferta enoturística, entre otros aspectos (Unwin, 1991; O’Neill, et al., 2002; Medina y Tresserras, 2008; Rodríguez, López-Guzmán y Sánchez, 2010; Parentau, 2010; Miranda y Fernández, 2011; López-Guzmán, Rodríguez y Vieira, 2013; Serrano, 2015; Salvat, 2018; entre otros).

Por otra parte, de acuerdo con Canalis et al. (2016), el turismo familiar es un segmento de mercado en crecimiento y bien valorado por su fidelidad en muchos destinos turísticos, por lo que, estos fomentan la creación de nuevos productos y servicios adaptados a sus necesidades. Además, el impacto económico del segmento familiar se ha incrementado en 18.552 millones de euros en 2019, un 1,3\% más que el año anterior. En este sentido, el aumento del gasto por parte de las familias se debe al aumento en un 5,84\% en la estancia 
media, al incremento del $13,35 \%$ del número de miembros que viajan y al mayor número de familias viajeras (un 2,05\% más) (Europapress, 2019).Aunque en los estudios de la demanda del enoturismo no es habitual prestar atención al segmento de las familias, cada vez son más las empresas de bodegas que ofrecen alguna propuesta específica para este segmento, detectando una posible oportunidad de negocio. De hecho, el último informe de análisis de la demanda de las Rutas del Vino de España muestra una evolución positiva de este colectivo, representando un $11,7 \%$ de los visitantes en el año 2017 y un 12,2\% en el 2018 (ACEVIN, 2028a).

También es importante destacar que, tal y como indican Schänzel y Yeoman (2015), los cambios sociales y económicos de las últimas décadas han transformado drásticamente la estructura familiar y su comportamiento en los viajes, siendo necesaria una revisión de sus características y necesidades por parte de las administraciones públicas y las empresas privadas que han apostado y apuestan por éste público.

En esta línea, el Patronato de Turismo de la Diputación de Tarragona apuesta por el estudio y desarrollo del enoturismo familiar a través del marco del Proyecto de Especialización y Competitividad Territorial (PECT) TurisTIC en familia, liderado por la Diputación de Tarragona y cofinanciado por el Fondo Europeo de Desarrollo Regional de la Unión Europea. La finalidad de este proyecto es convertir los destinos turísticos de la Costa Daurada y las Terres de l'Ebre en referencia innovadora global en el turismo familiar. El Patronato de Turismo es beneficiario de la operación "Viña en familia", una de las 11 operaciones que configuran este proyecto. Ésta es una idea innovadora que pretende superar la propuesta puntual de una bodega o empresa para convertirse en una proposición de carácter estratégico para la generación de experiencias alrededor del turismo del vino en el segmento de turismo familiar en los destinos de la Costa Daurada y las Terres de l'Ebre, diversificando su oferta con nuevos productos y creando actividades para las familias atendiendo de manera diferenciada las edades ${ }^{1}$. Así, en el marco de este proyecto, se impulsan investigaciones para conocer mejor las necesidades de las familias, identificar buenas prácticas en el enoturismo familiar y casos de éxito de otros destinos que ayuden a estimular la estructuración de esta nueva oferta.

En este contexto, las bodegas adquieren un componente de innovación de gran valor. Son muchos los autores que coinciden en que la innovación fomenta la competitividad, el crecimiento, la eficiencia y el éxito empresarial, consiguiendo efectos positivos en las empresas y organizaciones como la reducción de costos, la captación de nuevos clientes y/o la mejora del nivel de satisfacción del consumidor (Anton y Duro, 2009; Barbosa de Sousa y Dominique-Ferreira, 2012; Córdoba, Castillo y Castillo, 2018). La OMT (2019) define el gran valor que tiene la innovación turística, indicando que la introducción de nuevos componentes o perfeccionando los existente aporta ventajas a los actores turísticos y mejora el valor de las experiencias aportando competitividad y sostenibilidad al sector turístico y al territorio.

1 Este artículo está basado en los resultados de una investigación que forma parte del Proyecto de especialización y competitividad territorial (PECT) TurisTIC en familia, operación Viña en familia, referencia 2016.551.05 - PECT TurisTIC en Família - Vinya en Família, liderado por la Diputación de Tarragona y cofinanciado por el Fondo Europeo de Desarrollo Regional de la Unión Europea en el marco del Programa operativo FEDER de Cataluña 2014-2020, investigador principal Laura Rubia Albert. 
El conocimiento generado en esta investigación será trasladado a los agentes públicos y privados del sector enoturístico de las marcas turísticas Costa Daurada y Terres de l'Ebre que forman parte de la red de la operación Viña en familia del proyecto PECT TurisTIC en familia con la finalidad de fomentar la innovación y competitividad mediante esta segmentación.

Sobre la base de estos argumentos, el objetivo principal de este artículo es obtener las variables o indicadores que influyen en la configuración del producto familiar enoturístico con el fin de precisar e identificar las acciones que definen el segmento objeto de estudio. Para ello, en el presente estudio se realiza una revisión teórica del turismo enológico y las características y preferencias del segmento turístico familiar.

\section{TURISMO ENOLÓGICO: EL SEGMENTO FAMILIAR}

Los procesos de configuración de los destinos turísticos conducen al desarrollo de espacios que quedan determinados por las características de los territorios y la oferta que encontramos en ellos. De este modo, es evidente, que el desarrollo del turismo enológico adquiere una posición privilegiada debido al entorno donde se desarrolla su capacidad de resiliencia y sus propiedades culturales.

\subsection{La importancia del turismo enológico}

Los turistas están realizando viajes más cortos en el tiempo y más frecuentes, lo que implica que están visitando, además de los tradicionales destinos de sol y playa, nuevos lugares dónde encontrar nuevas experiencias (López-Guzmán, Rodríguez y Vieira, 2013, p.172). El enoturismo, también denominado turismo enológico, turismo del vino o turismo de bodegas, está viviendo una explosión desde hace un par de décadas causado principalmente por la recuperación del interés por el vino, por los productos de calidad y por conocer la procedencia de éstos y el patrimonio enológico (Unwin, 1991; Charters y Ali-Knight, 2000; Salvat, 2018). Por su parte, las empresas de los territorios vinícolas están aprovechando, a su vez, este fenómeno para dar a conocer su bodega y sus vinos, incrementar sus ventas, e incluso entrar en el negocio del turismo (Getz et al., 1999; Serrano, 2015; Salvat, 2018). Hay que indicar que, la importancia de la cultura vitivinícola se ha visto potenciada gracias a la creación en 1994 de la "Asociación Española de Pequeñas y Medianas Ciudades Vitivinícolas (ACEVIN)" y el cluster turístico "Rutas del Vino de España” .

Debido a su impacto, la comunidad científica se interesa por esta nueva actividad económica a inicios del nuevo siglo, definiendo el enoturismo como "la experiencia de visitar viñedos, conocer bodegas, asistir a festivales y a otros eventos en los cuales se degusta vino, y son el motivo principal del desplazamiento de los visitantes" (Hall et al., 2004; p.31). En esta línea, la Asociación Española de Enoturismo (AEE) propone como definición oficial de enoturismo: "Modalidad de turismo basada en desplazamientos a entornos vinícolas, con el propósito de conocer, disfrutar y compartir experiencias entorno a la Cultura del Vino" (AEE, 2019).

Existen diferentes corrientes y enfoques que clasifican el enoturismo como parte del turismo gastronómico, del turismo cultural, así como del turismo rural (Salvat, 2018). No 
obstante, cabe destacar que de las definiciones dadas por la Organización Mundial del Turismo (OMT, 2019) se desprende que el enoturismo se puede considerar un tipo de turismo gastronómico, como experiencia vinculada a un producto alimenticio; pero que se relaciona estrechamente también con el turismo cultural, como una puesta en valor del patrimonio enológico y la transmisión de una forma de vida; así como con el turismo rural, ya que puede incluir actividades en la naturaleza y sucede principalmente en entornos de baja densidad demográfica y agrícolas.

\subsection{El segmento del turismo familiar; preferencias y desarrollo}

De acuerdo con el informe Flash Eurobarometer (2016), en casi todos los países europeos, más de un 30\% de los encuestados viajan en familia. En este sentido, Suecia, Bélgica y Francia son los mercados con el mayor porcentaje, con un 41\%. En España, solamente el turismo familiar doméstico representa alrededor de 16.600 millones de euros al año del gasto turístico, y el turismo familiar internacional supone el $22 \%$ de las llegadas de turistas extranjeros (Canalis et al., 2016).

Los responsables de varios destinos turísticos a nivel mundial consideran el turismo familiar como un segmento estratégico, como demuestra la apuesta de muchos de ellos por la creación de sellos de calidad específicos de turismo familiar, tales como, "Famille Plus" en Francia, "Family Destination" en Suiza y "Sello de Turismo Familiar" en España. La Federación Española de Familias Numerosas (FEFN) es el organismo que gestiona el Sello de Turismo Familiar y elabora un estudio anual sobre las características de los viajes de las familias españolas y su impacto económico. En este sentido, las familias españolas realizan alrededor de 4 viajes al año, gastan un promedio de 268,04 euros al día por familia, se alojan sobretodo en hoteles, viajan mayormente en coche propio y los hijos influyen casi en un 30\% de las decisiones de viajar (FEFN y Expertus, 2018). Por su parte, Canalis et al. (2016) señalan que se trata de un segmento de la demanda maduro pero emergente en oferta.

En España, además del Sello de Turismo Familiar, existen otros sellos de calidad que certifican establecimientos y territorios adaptados a las familias. En concreto, en Cataluña, la Agencia Catalana de Turismo lanzó en el año 2003 el certificado "Destino de Turismo Familiar", que actualmente se denomina "Playa en familia" o "Montaña en familia". Estos sellos de calidad implican el cumplimiento por parte de las empresas de unos requisitos que se consideran necesarios para atender bien a las familias. Algunos ejemplos de estos criterios son: disponer de información de actividades para niños que se organizan en el destino, alquiler de coches y/o mochilas para niños, cunas y bañeras para niños, adhesivos en los cristales, mecanismos de seguridad para los enchufes, programación de actividades para niños, disponer de zona infantil y menú infantil (ACT, 2019). Otros sellos similares son: "Tour \& Kids" en la Comunidad Valenciana o "Galicia Destino Familiar" en Galicia.

Los cambios sociodemográficos y de hábitos de consumo de la sociedad de las últimas décadas, como el envejecimiento de la población o la incorporación de la mujer en el mercado laboral, han impactado en los patrones familiares, así como en la manera de organizar los viajes y hacer turismo. Algunos expertos (González-Durán, 2013; Schänzel, 
y Yeoman, 2015; ACT, 2019; Herrero-Diz et al., 2016; FEFN y Expertus, 2018; entre otros) coinciden en que las principales tendencias son:

- La emergencia de nuevas estructuras familiares (familias sin hijos, divorciados, homosexuales, abuelos y nietos, familias monoporentales, etc.)

- La realización de viajes multigeneracionales.

- Las familias buscan experiencias.

- El mayor papel de los niños en las decisiones de compra, en la recomendación y la creación de contenidos.

- La creencia de que las vacaciones son un elemento clave para reforzar las relaciones familiares.

- El hiperconsumismo y la mayor exigencia de los clientes más exigentes.

- Las necesidades de los niños son diferentes según su edad.

- Los niños valoran sobretodo la seguridad y el factor precio.

En España, el Estudio de Turismo familiar de la FEFN y Expertus (2018) muestra como los elementos más valorados por las familias a la hora de viajar son: encontrar alojamiento adaptado, seguridad, entorno agradable, actividades y restaurantes adaptados a sus necesidades (ver figura 1).

\section{Figura 1 \\ PREFERENCIAS PARA VIAJAR EN FAMILIA}

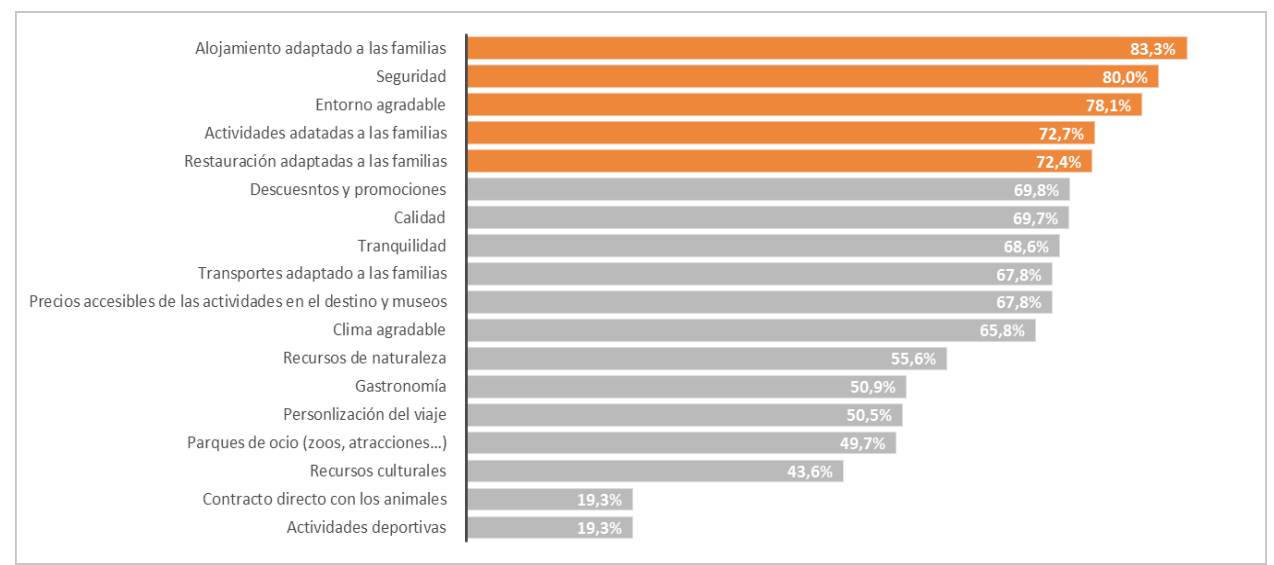

Fuente: VI Estudio Pautas de consumo turístico de las familias de España (FEFN y Expertus, 2018).

En el caso del enoturismo familiar (ver figura 2), el informe de la Demanda Turística de las Rutas del Vino (ACEVIN, 2018b) muestra que las familias es un segmento de mercado en crecimiento para los destinos enoturísticos en España, representando un 11,7\% en 2017 y un $12,2 \% 2018$. 


\section{Figura 2 \\ EVOLUCIÓN DE LA COMPOSICIÓN DEL GRUPO DE VIAJEROS}

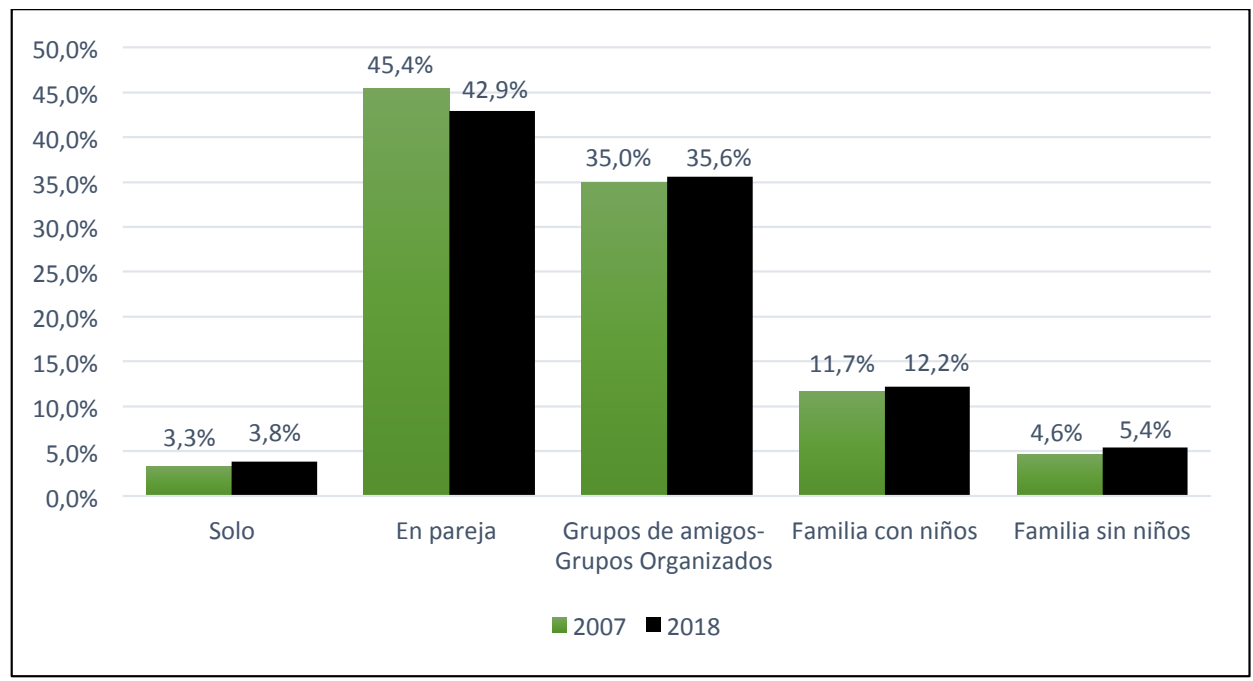

Fuente: Informe Análisis Demanda Rutas del Vino de España (ACEVIN, 2018b).

Por último, de acuerdo con la OMT (2016, pp. 9), una oferta de turismo de bodegas de calidad debe ser variada, contar historias que les diferencien y disponer de actividades para aquellos a los que no les guste el vino o no puedan degustarlo por distintos motivos. En definitiva, ofrecer productos o servicios ya no es suficiente. También es necesario proporcionar a los clientes experiencias satisfactorias (Berry et al., 2002).

\section{METODOLOGÍA}

En la revisión de investigaciones precedentes se han encontrado estudios que utilizan indicadores o variables que influyen en la elección de destinos o productos turísticos específicos (Femenía, 2011; Balderas, 2014; entre otros), si bien la literatura referente al segmento familiar es escasa y menos aún relacionada con el turismo enológico.

Para abordar el objetivo de esta investigación, durante los meses de julio y agosto de 2019 se ha llevado a cabo un análisis del contenido de las webs corporativas de las bodegas que presentan, entre su oferta turística, algún servicio o actividad para el segmento familiar.

De acuerdo con la Asociación Española de Ciudades del Vino (ACEVIN, 2017), la calidad de los vinos es el principal motivo de elección del destino para el enoturista. Este motivo ha sido determinante en esta investigación, donde se han analizado las dos regiones españolas que cuentan con una Denominación de Origen Calificada, La Rioja y el Priorat (y por extensión la Costa Daurada), así como Terres de l'Ebre y Penedès por proximidad al Priorat. Cabe remarcar un especial interés en los destinos Costa Daurada y 
Terres de l'Ebre, territorio en el que actúa el PECT TurisTIC en familia, proyecto en el que se enmarca esta investigación.

Por otro lado, con el interés de conocer y comparar las tendencias en otras regiones pioneras, se decide también investigar otras regiones internacionales, como Burdeos en Francia y Napa Valley-Sonoma en Estados Unidos. De acuerdo con Girini (2017, pp. 2): "de todas las regiones internacionales del vino, Burdeos (Francia) y el Valle de Napa (EE. $U U$.) son las más visitadas". Burdeos es un destino enoturístico referente en Europa donde el patrimonio enológico adquiere un papel muy relevante (Miranda y Fernández, 2011). Tanto es así, que la Jurisdicción de Saint-Émilion fue el primer paisaje vitícola inscrito al Patrimonio Mundial de la Humanidad por la UNESCO como "paisaje cultural" (Salvat, 2018). Por su parte, Los Valles de Napa y de Sonoma son el destino enoturístico pionero del llamado "Nuevo Mundo" (Miranda y Fernández, 2011; Salvat, 2018). Tan solo Napa Valley recibe alrededor de 4 millones de visitantes, de los cuales un $20 \%$ aproximadamente son familias con niños (información obtenida de la web de Visit Napa Valley).

Para la identificación de experiencias o actividades enoturísticas dirigidas a familias, se han seleccionado las webs corporativas de 57 empresas bodegueras que tienen algún servicio para las familias, en concreto: 34 en España (12 en La Rioja, y 22 en la Costa Daurada, Terres de l'Ebre y Penedés); 11 en Burdeos (Francia); y 12 en Napa Valley y Sonoma (Estados Unidos). Dicha selección se ha realizado de forma aleatoria pero teniendo en cuenta la localización geográfica, la oferta dirigida al segmento familiar y el nivel de innovación de las actividades.

El análisis de las páginas webs de las bodegas identificadas en diferentes destinos enoturísticos permite observar aquellas con mayor grado de innovación en el desarrollo de sus productos, sin embargo, no permite medir aspectos relevantes de las innovaciones, tales como, las fuentes de información, los motivos de su impulso o los obstáculos encontrados durante el proceso de innovación. Por ese motivo, se han visitado bodegas y se han realizado entrevistas semiestructuradas en algunas de las experiencias con mayor grado de innovación. Este criterio se ha basado en los indicadores estudiados, considerando un grado de innovación elevada a aquellas que cuentan con una innovación tecnológica o que utilizan recursos adaptados a los niños, que cuentan con varios servicios para las familias, ofrecen programación regular, información, idiomas, reserva y venta en línea, o que ofrecen una experiencia diferenciada y original. También se ha tenido en cuenta si han sido galardonados con premios de innovación o mencionados en revistas y jornadas como casos de éxito.

Por ello, se ha entrevistado y visitado 10 bodegas de diferentes territorios con el objetivo de conocer las diferencias, ya que cada territorio tiene sus propias dinámicas y peculiaridades. Finalmente, se ha entrevistado al responsable de la "app" Ampélograf, una aplicación móvil dirigida a las familias que desean visitar bodegas y que ofrece a estas últimas la posibilidad de dar un servicio más personalizado a este segmento de demanda. De este modo, aunque no se trate de una bodega, es un caso ejemplar de innovación en el enoturismo familiar del cual se puede aprender. En la tabla 1 se detallan el nombre de las bodegas, la fecha de la visita o entrevista y la técnica utilizada para obtener la información.

En las visitas realizadas se ha llevado a cabo la recogida de información a través de la técnica de observación participante definida como el método interactivo de recogida 
de información que requiere una implicación del observador en los acontecimientos o fenómenos de lo que es testigo (Rodríguez, Gil y García (1999, p. 165). Estas visitas han dependido de la disponibilidad de las experiencias familiares durante el verano de 2019, época en la que se ha realizado el trabajo de campo. Por otra parte, se ha entrevistado y visitado bodegas de diferentes territorios para observar diferencias, ya que cada territorio tiene sus propias dinámicas e idiosincrasia.

Tabla 1

BODEGAS ENTREVISTADAS Y/O VISITADAS

\begin{tabular}{llll}
\hline Bodegas & Destino turístico & Visita & Técnica de análisis \\
\hline AvgvstvsForvm & $\begin{array}{l}\text { Costa Daurada } \\
\text { (Cataluña) }\end{array}$ & $10 / 8 / 2019$ & $\begin{array}{l}\text { Entrevista y observación } \\
\text { participante }\end{array}$ \\
\hline EstolVerd & $\begin{array}{l}\text { Costa Daurada } \\
\text { (Cataluña) }\end{array}$ & $14 / 8 / 2019$ & Entrevista \\
\hline Vivanco & La Rioja & $16 / 8 / 2019$ & Entrevista \\
\hline El Fabulista - Villa Lucía & $\begin{array}{l}\text { La Rioja Alavesa } \\
\text { (País Vasco) }\end{array}$ & $19 / 8 / 2019$ & Observación participante \\
\hline Bohedal & La Rioja & $20 / 8 / 2019$ & Observación participante \\
\hline Bodegas Franco-Española & La Rioja & $21 / 8 / 2019$ & Entrevista \\
\hline Bodegas Valdemar & $\begin{array}{l}\text { La Rioja Alavesa } \\
\text { (País Vasco) }\end{array}$ & $21 / 8 / 2019$ & $\begin{array}{l}\text { Entrevista y observación } \\
\text { partipante }\end{array}$ \\
\hline Bodegas Freixenet & Penedès (Cataluña) & $25 / 82019$ & $\begin{array}{l}\text { Entrevista y observación } \\
\text { participante }\end{array}$ \\
\hline Nadal & $\begin{array}{l}\text { Penedès (Penedès, } \\
\text { Cataluña) }\end{array}$ & $27 / 8 / 2019$ & Entrevista \\
\hline App Ampélograf & Occitania (Francia) & $28 / 8 / 2019$ & Entrevista \\
\hline Buena Vista Winery & $\begin{array}{l}\text { Sonoma (Estados } \\
\text { Unidos) }\end{array}$ & $31 / 8 / 2019$ & Entrevista \\
\hline
\end{tabular}

Fuente. Elaboración propia.

Las cuestiones solicitadas en las entrevistas realizadas han sido; servicios y productos ofrecidos para las familias en la bodega, características de la/s propuesta/s para las familias, cómo fue el proceso de creación de la experiencia, qué importancia tienen las familias en el global de la actividad enoturística de la bodega tanto a nivel de volumen como económico, qué interés y potencial ven en el segmento familiar, conocer los aspectos clave del éxito de su propuesta, los puntos que creen que deberían mejorar y las dificultades encontradas para consolidar la actividad. También, el perfil de las familias que les visitan, las motivaciones principales de las familias que les visitan y las diferencias de sus necesidades y deseos según las edades de los niños. 


\section{RESULTADOS}

\subsection{Análisis de las páginas webs de las empresas bodegueras}

Para el análisis comparativo de los diferentes destinos de enoturismo o experiencias enoturísticas enfocadas en el segmento familiar, se ha realizado una comparación de las páginas webs de las mencionadas bodegas en función de los indicadores o variables de la experiencia seleccionada orientada al turismo familiar. Los indicadores analizados son mayormente descriptivos y buscan conocer las singularidades de las nuevas propuestas de las bodegas, así como la caracterización y grado de innovación. En la tabla 2 se detallan las bodegas seleccionadas, el nombre de la experiencia, su descripción y la web de donde se ha extraído la información. Si se analizan las principales singularidades de las experiencias se observa que existe bastante variedad entre las propuestas de enoturismo familiar. Las principales categorías son yincanas, talleres, actividades físicas, experiencias de ingenio y creatividad, relacionado con los animales, zonas de juego y museos.

\section{Tabla 2}

\section{BODEGAS CON EXPERIENCIAS DE ENOTURISMO FAMILIAR IDENTIFICADAS EN EL ESTUDIO}

\begin{tabular}{|c|c|c|c|c|}
\hline Bodega & $\begin{array}{c}\text { Destino } \\
\text { enoturístico }\end{array}$ & $\begin{array}{c}\text { Nombre de la } \\
\text { experiencia }\end{array}$ & Descripción & Web \\
\hline Buil\&Giné & $\begin{array}{l}\text { CATALUÑA } \\
\text { - COSTA } \\
\text { DAURADA }\end{array}$ & $\begin{array}{l}\text { Aventura del } \\
\text { vino }\end{array}$ & $\begin{array}{l}\text { Juego de pruebas entorno } \\
\text { a la elaboración del vino. } \\
\text { Se organiza por equipos e } \\
\text { incluye pruebas tanto a las } \\
\text { viñas como la bodega como } \\
\text { hacer vendimia, seleccionar } \\
\text { la uva, embotellar, etiquetar } \\
\text { y degustar a ciegas. La } \\
\text { actividad se adapta a todas } \\
\text { las edades. }\end{array}$ & $\begin{array}{l}\text { http://www.builgine.com/ } \\
\text { es/page/activitats }\end{array}$ \\
\hline Pagos de Híbera & $\begin{array}{l}\text { CATALUÑA } \\
\text { - TERRES } \\
\text { DE L'EBRE }\end{array}$ & $\begin{array}{l}\text { Visita infantil } \\
\text { en la Catedral } \\
\text { del Vi }\end{array}$ & $\begin{array}{l}\text { Visita guiada del } \\
\text { edificio modernista y } \\
\text { sus instalaciones que } \\
\text { se complementa con un } \\
\text { audiovisual de apoyo y } \\
\text { cata de vinos. Los niños } \\
\text { durante el recorrido realizan } \\
\text { una búsqueda del tesoro y } \\
\text { mientras los padres hacen } \\
\text { la degustación, junto con } \\
\text { la monitora y las piezas } \\
\text { encontradas, harán un } \\
\text { puzle que imita el friso de } \\
\text { la fachada. La actividad } \\
\text { se termina con la creación } \\
\text { de etiquetas de vino } \\
\text { personalizadas que podrán } \\
\text { llevarse para regalar. }\end{array}$ & $\begin{array}{l}\text { https://catedraldelvi.com/ } \\
\text { es/visitas-degustaciones/ }\end{array}$ \\
\hline
\end{tabular}




\begin{tabular}{|c|c|c|c|c|}
\hline Bodega & $\begin{array}{c}\text { Destino } \\
\text { enoturístico }\end{array}$ & $\begin{array}{c}\text { Nombre de la } \\
\text { experiencia }\end{array}$ & Descripción & Web \\
\hline Celler Cal Menescal & $\begin{array}{l}\text { CATALUÑA } \\
\text { - TERRES } \\
\text { DE L'EBRE }\end{array}$ & $\begin{array}{l}\text { Enoturismo en } \\
\text { familia }\end{array}$ & $\begin{array}{l}\text { Visita a un museo sobre } \\
\text { la elaboración del vino } \\
\text { y aceite, degustación de } \\
\text { mosto y vino para los } \\
\text { padres, juego de aromas } \\
\text { compartido entre padres e } \\
\text { hijos, actividad de pintura } \\
\text { y dibujo para los niños. } \\
\text { También ofrecen una ruta } \\
\text { guiada de } 10 \text { km con bici } \\
\text { eléctrica que sale desde la } \\
\text { bodega y hace paradas en } \\
\text { las viñas, que se adapta a la } \\
\text { época del año y a la forma } \\
\text { física del grupo. }\end{array}$ & $\begin{array}{l}\text { https://www. } \\
\text { cellermenescal.com/es/ } \\
\text { enoturismo/enoturisme- } \\
\text { en-familia }\end{array}$ \\
\hline Celler El Masroig & $\begin{array}{l}\text { CATALUÑA } \\
\text { - COSTA } \\
\text { DAURADA }\end{array}$ & $\begin{array}{l}\text { Visita a las } \\
\text { Minas de } \\
\text { Bellmunt y } \\
\text { Celler Masroig }\end{array}$ & $\begin{array}{l}\text { Visita combinada al Museo } \\
\text { de las Minas de Bellmunt } \\
\text { del Priorat y visita a las } \\
\text { instalaciones de la bodega } \\
\text { Masroig. El recorrido } \\
\text { finaliza con cata de } 3 \text { vinos } \\
\text { y degustación de aceite. }\end{array}$ & $\begin{array}{l}\text { https://cellermasroig.com/ } \\
\text { es/actividades/ }\end{array}$ \\
\hline CellerRonadelles & $\begin{array}{l}\text { CATALUÑA } \\
\text { - COSTA } \\
\text { DAURADA }\end{array}$ & $\begin{array}{l}\text { Visita } \\
\text { teatralizada }\end{array}$ & $\begin{array}{l}\text { Descubrimiento del pasado } \\
\text { de la elaboración del vino } \\
\text { en Cornudella de Montsant } \\
\text { y de las tierras de los } \\
\text { alrededores mediante una } \\
\text { visita teatralizada al pueblo, } \\
\text { los viñedos y la bodega. } \\
\text { Finaliza con degustación } \\
\text { de vino. }\end{array}$ & $\begin{array}{l}\text { https://www.ronadelles. } \\
\text { com/es/enoturismo }\end{array}$ \\
\hline CellersAvgvstvsForvm & $\begin{array}{l}\text { CATALUÑA } \\
\text { - COSTA } \\
\text { DAURADA }\end{array}$ & Visita familiar & $\begin{array}{l}\text { Actividad para niños } \\
\text { de } 4 \text { a } 10 \text { años (siempre } \\
\text { acompañados) lúdica y } \\
\text { didáctica en la cual un } \\
\text { monitor que personifica } \\
\text { un gladiador romano les } \\
\text { entrega un mapa y obsequio } \\
\text { que les adentra en la } \\
\text { época romana. Se realizan } \\
\text { pruebas, una cata de mosto } \\
\text { y de vinagres y aprenden los } \\
\text { procesos de la elaboración } \\
\text { del vino. }\end{array}$ & $\begin{array}{l}\text { https://www. } \\
\text { avgvstvsforvm. } \\
\text { com/es/actividades- } \\
\text { enoturismo/268-actividad- } \\
\text { familiar-para-ninos-de-4- } \\
\text { 10-anos-acompanantes }\end{array}$ \\
\hline $\begin{array}{l}\text { Cooperativa Falset- } \\
\text { Marçà }\end{array}$ & $\begin{array}{l}\text { CATALUÑA } \\
\text { - COSTA } \\
\text { DAURADA }\end{array}$ & $\begin{array}{l}\text { Visita } \\
\text { teatralizada }\end{array}$ & $\begin{array}{l}\text { Visita teatralizada para } \\
\text { grupos, para familias y } \\
\text { para no iniciados. Un guía } \\
\text { representa un trabajador que } \\
\text { con humor les explica los } \\
\text { detalles arquitectónicos de } \\
\text { la bodega y el proceso de } \\
\text { la elaboración del vino. La } \\
\text { visita finaliza con una cata. }\end{array}$ & $\begin{array}{l}\text { https://www.etim.cat/ca/ } \\
\text { activitat/visites-al-celler }\end{array}$ \\
\hline
\end{tabular}




\begin{tabular}{|c|c|c|c|c|}
\hline Bodega & $\begin{array}{c}\text { Destino } \\
\text { enoturístico }\end{array}$ & $\begin{array}{c}\text { Nombre de la } \\
\text { experiencia }\end{array}$ & Descripción & Web \\
\hline EstolVerdCeller & $\begin{array}{l}\text { CATALUÑA } \\
\text { - COSTA } \\
\text { DAURADA }\end{array}$ & Orient-tast & $\begin{array}{l}\text { Experiencia enoturística en } \\
\text { grupo que consiste de una } \\
\text { actividad de senderismo } \\
\text { y yincana donde hay que } \\
\text { encontrar vinos escondidos } \\
\text { en varias rutas que pasan } \\
\text { por las fincas de EstolVerd } \\
\text { y evaluar los conocimientos } \\
\text { de vino mediante una } \\
\text { aplicación. Actividad } \\
\text { adaptada también para } \\
\text { niños. }\end{array}$ & $\begin{array}{l}\text { http://www.estolverd.cat/ } \\
\text { orien-tast/\# }\end{array}$ \\
\hline Mas Vicenç & $\begin{array}{l}\text { CATALUÑA } \\
\text { - COSTA } \\
\text { DAURADA }\end{array}$ & $\begin{array}{l}\text { Walk and Wine } \\
\text { (guiado y a tu } \\
\text { aire) }\end{array}$ & $\begin{array}{l}\text { Actividad que combina } \\
\text { el deporte, el vino y la } \\
\text { gastronomía entre los } \\
\text { viñedos de los alrededores } \\
\text { de la bodega. Esta } \\
\text { experiencia permite conocer } \\
\text { la técnica de la marcha } \\
\text { nórdica así como las tierras } \\
\text { donde se cultiva la uva y } \\
\text { sus variedades. Se puede } \\
\text { hacer guiada o a tu aire, se } \\
\text { puede escoger entre dos } \\
\text { rutas, una de } 3,65 \text { km y otra } \\
\text { de } 1,60 \text { km. En uno de los } \\
\text { puntos marcados de la ruta } \\
\text { encontrarán una botella } \\
\text { para realizar cata de vino y } \\
\text { al final de la ruta también } \\
\text { podrán catar vinos en las } \\
\text { instalaciones de la bodega. }\end{array}$ & $\begin{array}{l}\text { https://masvicens.com/es/ } \\
\text { enoturismo-en-tarragona/ }\end{array}$ \\
\hline Vinícola de Nulles & $\begin{array}{l}\text { CATALUÑA } \\
\text { - COSTA } \\
\text { DAURADA }\end{array}$ & $\begin{array}{l}\text { Ruta en carro } \\
\text { entre viñas }\end{array}$ & $\begin{array}{l}\text { Ruta en carro de caballos } \\
\text { entre viñedos que permite a } \\
\text { toda la familia descubrir la } \\
\text { zona con secretos como un } \\
\text { poblado Íbero o la pedanía } \\
\text { de Casafort. Después de la } \\
\text { ruta, se realiza una visita } \\
\text { a la Catedral del Vino de } \\
\text { Nulles (Adernats) y se catan } \\
\text { vinos y cavas acompañadas } \\
\text { de pan artesano, avellanas y } \\
\text { aceite de la zona. }\end{array}$ & $\begin{array}{l}\text { http://www.adernats.cat/ } \\
\text { es/enoturismo }\end{array}$ \\
\hline CellerVins Suñer & $\begin{array}{l}\text { CATALUÑA } \\
\text { - TERRES } \\
\text { DE L'EBRE }\end{array}$ & Wine en kayak & $\begin{array}{l}\text { Consiste en un paseo en } \\
\text { kayak por el río Ebro donde } \\
\text { se podrá disfrutar de la } \\
\text { vegetación y aves. También } \\
\text { se explica la historia de la } \\
\text { zona y luego se visita la } \\
\text { bodega Vins Suñer donde } \\
\text { se explica la elaboración de } \\
\text { sus vinos. }\end{array}$ & $\begin{array}{l}\text { http://vinsiolisuner.com/ } \\
\text { es/wine-en-kayak-la- } \\
\text { actividad-perfecta/ }\end{array}$ \\
\hline
\end{tabular}




\begin{tabular}{|c|c|c|c|c|}
\hline Bodega & $\begin{array}{c}\text { Destino } \\
\text { enoturístico }\end{array}$ & $\begin{array}{c}\text { Nombre de la } \\
\text { experiencia }\end{array}$ & Descripción & Web \\
\hline CellerVilarnau & $\begin{array}{l}\text { CATALUÑA } \\
\text { - PENEDÈS }\end{array}$ & Visita familiar & $\begin{array}{l}\text { Durante la "Visita } \\
\text { Familiar", mientras los } \\
\text { adultos disfrutan de la } \\
\text { Visita Espíritu Vilarnau } \\
\text { los más pequeños viven y } \\
\text { experimentan el viñedo con } \\
\text { una monitora especializada, } \\
\text { probando el mosto y } \\
\text { descubriendo la magia } \\
\text { que transforma este mosto } \\
\text { en vino y cava. La visita } \\
\text { termina con un taller de } \\
\text { manualidades. A parte } \\
\text { de esta visita específica, } \\
\text { Vilarnau ofrece otras visitas } \\
\text { y paquetes que pueden ser } \\
\text { de interés para las familias: } \\
\text { Visita combinada Cavas } \\
\text { Vilarnau y Chocolates } \\
\text { Simón Coll, Visita } \\
\text { combinada Cava Vilarnau } \\
\text { y Albet i Noya, Visita } \\
\text { combinada Cavas Vilarnau } \\
\text { y Centro de Interpretación } \\
\text { del Cava, VisitaPoda, } \\
\text { Visita de Atardecer, Visita } \\
\text { Vilarnau en Helicóptero, } \\
\text { Visita Pisado de Uva, Visita } \\
\text { Calçotada. }\end{array}$ & $\begin{array}{l}\text { https://www.vilarnau.es/ } \\
\text { es/experiencies/visites/ } \\
\text { fam\%C3\%ADlies }\end{array}$ \\
\hline Llàgrimad'Or & $\begin{array}{l}\text { CATALUÑA } \\
\text { - PENEDÈS }\end{array}$ & $\begin{array}{l}\text { Barbacoa y } \\
\text { parque infantil }\end{array}$ & $\begin{array}{l}\text { Esta bodega ofrece un } \\
\text { amplio espacio al aire libre } \\
\text { preparado con barbacoas, } \\
\text { parque infantil para los } \\
\text { más pequeños y zonas para } \\
\text { jugar a la pelota, así como } \\
\text { mesas y sillas, para que los } \\
\text { visitantes puedan realizar } \\
\text { picnic. Las familias podrán } \\
\text { disfrutar de este espacio, así } \\
\text { como realizar una visita a } \\
\text { la bodega. }\end{array}$ & $\begin{array}{l}\text { http://www.llagrimador. } \\
\text { com/ca/enoturisme }\end{array}$ \\
\hline Cellers Carol Vallès & $\begin{array}{l}\text { CATALUÑA } \\
\text { - PENEDÈS }\end{array}$ & $\begin{array}{l}\text { Ruta en bici: } \\
\text { descubre el } \\
\text { Penedès sobre } \\
\text { ruedas }\end{array}$ & $\begin{array}{l}\text { Esta actividad incluye } \\
\text { una ruta en bicicleta por } \\
\text { los viñedos que rodean la } \\
\text { bodega, una visita guiada } \\
\text { por la viñas y el interior } \\
\text { de la bodega, explicación } \\
\text { del proceso artesanal de la } \\
\text { elaboración del cava, una } \\
\text { degustación y un pica-pica } \\
\text { con productos Km } 0 \text {. }\end{array}$ & $\begin{array}{l}\text { https://cellerscarol.com/ } \\
\text { enoturisme/ }\end{array}$ \\
\hline
\end{tabular}




\begin{tabular}{|c|c|c|c|c|}
\hline Bodega & $\begin{array}{c}\text { Destino } \\
\text { enoturístico }\end{array}$ & $\begin{array}{c}\text { Nombre de la } \\
\text { experiencia }\end{array}$ & Descripción & Web \\
\hline Miquel Jané & $\begin{array}{l}\text { CATALUÑA } \\
\text { - PENEDÈS }\end{array}$ & $\begin{array}{l}\text { Enoturismo en } \\
\text { familia }\end{array}$ & $\begin{array}{l}\text { Esta actividad incluye un } \\
\text { paseo por las viñas donde } \\
\text { se dan explicaciones } \\
\text { sobre viticultura, una } \\
\text { visita a la bodega, un } \\
\text { taller sensorial donde los } \\
\text { niños experimentan con } \\
\text { diferentes texturas de tierra, } \\
\text { degustación de zumo de } \\
\text { uva y aromas de diferentes } \\
\text { frutas, flores... Incluye una } \\
\text { cata de } 4 \text { vinos para los } \\
\text { padres y un aperitivo con } \\
\text { productos de la región. La } \\
\text { bodega ofrece también la } \\
\text { posibilidad de quedarse a } \\
\text { comer en la finca y probar } \\
\text { el menú degustación. }\end{array}$ & $\begin{array}{l}\text { https://www.miqueljane. } \\
\text { com/PBCPPlayer. } \\
\text { asp?ID=1682918 }\end{array}$ \\
\hline Segura Viudas & $\begin{array}{l}\text { CATALUÑA } \\
\text { - PENEDÈS }\end{array}$ & $\begin{array}{l}\text { Visita Eno- } \\
\text { natura }\end{array}$ & $\begin{array}{l}\text { Esta actividad no es } \\
\text { específica para familias pero } \\
\text { los niños son bienvenidos. } \\
\text { Consiste en una mañana } \\
\text { de trekking o bicicletas } \\
\text { eléctricas para pasear por } \\
\text { los viñedos de Segura } \\
\text { Viudas. Este recorrido } \\
\text { permite conocer el paisaje } \\
\text { y conocer la filosofía de la } \\
\text { bodega. También se degusta } \\
\text { un vino, se visita la bodega } \\
\text { y se realiza un desayuno } \\
\text { local tradicional. }\end{array}$ & $\begin{array}{l}\text { https://seguraviudas.com/ } \\
\text { ca/enoturisme-trekking- } \\
\text { bicicleta-segura-viudas }\end{array}$ \\
\hline Albet i Noya & $\begin{array}{l}\text { CATALUÑA } \\
\text { - PENEDÈS }\end{array}$ & $\begin{array}{l}\text { Visita a la } \\
\text { bodega en } \\
\text { familia }\end{array}$ & $\begin{array}{l}\text { Esta visita acerca a padres } \\
\text { y niños a la viña y el vino, } \\
\text { al proceso de elaboración } \\
\text { de los vinos ecológicos y } \\
\text { la historia de la bodega. } \\
\text { Realizan una visita en } \\
\text { la bodega y mientras los } \\
\text { padres catan } 3 \text { vinos, los } \\
\text { niños realizan un taller } \\
\text { dinámico guiado por } \\
\text { monitores. }\end{array}$ & $\begin{array}{l}\text { https://www.albetinoya. } \\
\text { cat/viscuriosos.php }\end{array}$ \\
\hline
\end{tabular}




\begin{tabular}{|c|c|c|c|c|}
\hline Bodega & $\begin{array}{c}\text { Destino } \\
\text { enoturístico }\end{array}$ & $\begin{array}{c}\text { Nombre de la } \\
\text { experiencia }\end{array}$ & Descripción & Web \\
\hline Nadal & $\begin{array}{l}\text { CATALUÑA } \\
\text { - PENEDÈS }\end{array}$ & $\begin{array}{l}\text { El misterio de } \\
\text { Can Nadal de la } \\
\text { Boadella }\end{array}$ & $\begin{array}{l}\text { Actividad dirigida a niños } \\
\text { de } 4 \text { a } 12 \text { años que consiste } \\
\text { en un juego de pistas por } \\
\text { la bodega y los viñedos. } \\
\text { Acompañados de un } \\
\text { monitor, en grupos de } 5 \\
\text { a } 12 \text { niños, resuelven los } \\
\text { enigmas de una misteriosa } \\
\text { narración mientras conocen, } \\
\text { de forma entretenida, cómo } \\
\text { se trabaja la viña y cómo se } \\
\text { elaboran el vino y el cava. } \\
\text { Al final, tienen maridaje } \\
\text { de chocolate y mosto } \\
\text { procedente de los viñedos } \\
\text { que han pisado. Los padres } \\
\text { pueden elegir una de las } \\
\text { visitas estándar o maridajes. }\end{array}$ & $\begin{array}{l}\text { https://nadal.com/ } \\
\text { enoturisme-i-oci/visites- } \\
\text { nadal/ }\end{array}$ \\
\hline Freixenet & $\begin{array}{l}\text { CATALUÑA } \\
\text { - PENEDÈS }\end{array}$ & Visita familiar & $\begin{array}{l}\text { La visita familiar consiste } \\
\text { en una visita teatralizada } \\
\text { en la cual la guía interpreta } \\
\text { al niño de los anuncios } \\
\text { de Freixenet. La guía } \\
\text { acompaña al grupo por las } \\
\text { instalaciones de la bodega } \\
\text { explicando la historia y } \\
\text { la elaboración del cava, } \\
\text { siempre con un lenguaje } \\
\text { adaptado a los niños y } \\
\text { haciéndoles participar. } \\
\text { Una parte de la visita se } \\
\text { hace con un trenecillo, } \\
\text { también existe un espacio } \\
\text { de exposición donde se } \\
\text { aprende a elaborar el cava y } \\
\text { se les regala una libreta con } \\
\text { colores al final de la visita. } \\
\text { Los padres degustan dos } \\
\text { copas de cava y los niños } \\
\text { cava sin alcohol. }\end{array}$ & $\begin{array}{l}\text { https://www.freixenet.es/ } \\
\text { es/enoturismo/bodegas- } \\
\text { freixenet/visita-las- } \\
\text { bodegas }\end{array}$ \\
\hline Ferré i Catasús & $\begin{array}{l}\text { CATALUÑA } \\
\text { - PENEDÈS }\end{array}$ & $\begin{array}{l}\text { Terraza y circo } \\
\text { para niños }\end{array}$ & $\begin{array}{l}\text { Taller de circo para los } \\
\text { niños. Mientras, los padres } \\
\text { pueden sentarse en la } \\
\text { terraza y disfrutar de vinos } \\
\text { y vermuts. }\end{array}$ & $\begin{array}{l}\text { http://www.ferreicatasus } \\
\text { com/ca/actividades }\end{array}$ \\
\hline Maspujadó & $\begin{array}{l}\text { CATALUÑA } \\
\text { - PENEDÈS }\end{array}$ & Visita familiar & $\begin{array}{l}\text { Visita dirigida a los niños } \\
\text { en la que se explica la } \\
\text { elaboración del cava y se } \\
\text { hacen dibujos. Los padres } \\
\text { degustan Cava y los niños } \\
\text { mosto o otras bebidas. }\end{array}$ & $\begin{array}{l}\text { http://www.maspujado. } \\
\text { com/es/cava-maspujado/ }\end{array}$ \\
\hline
\end{tabular}




\begin{tabular}{|c|c|c|c|c|}
\hline Bodega & $\begin{array}{c}\text { Destino } \\
\text { enoturístico }\end{array}$ & $\begin{array}{c}\text { Nombre de la } \\
\text { experiencia }\end{array}$ & Descripción & Web \\
\hline CellerVell & $\begin{array}{l}\text { CATALUÑA } \\
\text { - PENEDÈS }\end{array}$ & Cavatren $\mathrm{H} 0$ & $\begin{array}{l}\text { Cava TrenH0 de CellerVell } \\
\text { es una maqueta de trenes } \\
\text { que reproduce el entorno } \\
\text { del Penedès, caracterizado } \\
\text { por los viñedos de los } \\
\text { que nace el cava que } \\
\text { está ubicada dentro de } \\
\text { la bodega. La maqueta } \\
\text { ferroviaria se puede } \\
\text { visitar los fines de semana } \\
\text { haciendo un recorrido por } \\
\text { las cavas donde se descubre } \\
\text { el proceso de elaboración } \\
\text { artesanal con una cata al } \\
\text { final de la visita. }\end{array}$ & $\begin{array}{l}\text { http://www.cellervell. } \\
\text { com/es/contenido/25- } \\
\text { cavatren-h0 }\end{array}$ \\
\hline $\begin{array}{l}\text { EI Fabulista y Centro } \\
\text { temático del vino villa } \\
\text { lucía }\end{array}$ & $\begin{array}{l}\text { LA RIOJA } \\
\text { (ALAVESA) }\end{array}$ & $\begin{array}{l}\text { El Fabulista y } \\
\text { los niños }\end{array}$ & $\begin{array}{l}\text { La bodega El Fabulista } \\
\text { ha editado un cuento de } \\
\text { fábulas que explican en la } \\
\text { visita familiar que ofrecen. } \\
\text { Además, forman parte } \\
\text { del mismo grupo que el } \\
\text { Centro temático del vino } \\
\text { de Villa Lucía. Situado en } \\
\text { una antigua finca de recreo } \\
\text { del fabulista Samaniego, } \\
\text { concentra toda la historia } \\
\text { y rituales del vino. La } \\
\text { visita es dinámica con } \\
\text { efectos audiovisuales, } \\
\text { catas virtuales de aromas } \\
\text { y colores y la experiencia } \\
\text { sensorial en 4D "En tierra } \\
\text { de sueños", que ha recibido } \\
17 \text { premios internacionales, } \\
\text { en la que un "Vinfo" } \\
\text { (duende del vino) invita } \\
\text { al público a conocer el } \\
\text { patrimonio y la cultura de la } \\
\text { Rioja Alavesa. }\end{array}$ & $\begin{array}{l}\text { http://bodegaelfabulista. } \\
\text { com/ }\end{array}$ \\
\hline Bodegas David Moreno & LA RIOJA & Vincana & $\begin{array}{l}\text { La Vincana es un juego } \\
\text { de pistas y enigmas } \\
\text { relacionados con el } \\
\text { vino. Para resolverlos es } \\
\text { imprescindible participar } \\
\text { y trabajar en equipo. La } \\
\text { Vincana está orientada al } \\
\text { turismo familiar y a grupos } \\
\text { de amigos. Se pueden } \\
\text { personalizar las pruebas y } \\
\text { recorridos. }\end{array}$ & $\begin{array}{l}\text { http://www.davidmoreno. } \\
\text { es/actividades/vincana/ }\end{array}$ \\
\hline
\end{tabular}




\begin{tabular}{|c|c|c|c|c|}
\hline Bodega & $\begin{array}{c}\text { Destino } \\
\text { enoturístico }\end{array}$ & $\begin{array}{c}\text { Nombre de la } \\
\text { experiencia }\end{array}$ & Descripción & Web \\
\hline Vivanco & LA RIOJA & $\begin{array}{l}\text { Talleres } \\
\text { infantiles }\end{array}$ & $\begin{array}{l}\text { Talleres creativos y lúdicos } \\
\text { para acercar a los niños } \\
\text { a la Cultura del Vino. } \\
\text { Los talleres se adaptan } \\
\text { a la estación del año, } \\
\text { actualmente ofrecen el taller } \\
\text { "Brotes, hojas y flores" } \\
\text { que consiste en conocer } \\
\text { los primeros brotes de la } \\
\text { vid, los sarmientos y las } \\
\text { hojas. Entre los talleres } \\
\text { anteriores hay "Invierno } \\
\text { en el viñedo", "El otoño } \\
\text { y la vendimia", "Verano } \\
\text { en el viñedo". Los talleres } \\
\text { infantiles se diseñan en base } \\
\text { al fruto de la observación, } \\
\text { la investigación y la } \\
\text { cooperación. También } \\
\text { tienen el Museo de la } \\
\text { Cultura del Vino con juegos } \\
\text { interactivos para niños. }\end{array}$ & $\begin{array}{l}\text { https:// } \\
\text { vivancoculturadevino.es/ } \\
\text { es/experiencias/kids/ }\end{array}$ \\
\hline Bohedal & LA RIOJA & $\begin{array}{l}\text { Talleres } \\
\text { creativos }\end{array}$ & $\begin{array}{l}\text { Bohedal dispone de una } \\
\text { ludoteca para niños donde } \\
\text { mientras los adultos } \\
\text { disfrutan de la visita a la } \\
\text { bodega, los niños aprenden } \\
\text { y disfrutan con talleres } \\
\text { creativos en los que diseñan } \\
\text { una etiqueta para una } \\
\text { botella pintada con vino. } \\
\text { Incluye degustación de } \\
\text { mosto y un aperitivo. }\end{array}$ & $\begin{array}{l}\text { https://bohedal.com/ } \\
\text { enoturismo/experiencias/ } \\
\text { talleres-creativos/ }\end{array}$ \\
\hline Valdemar & $\begin{array}{l}\text { LA RIOJA } \\
\text { (ALAVESA) }\end{array}$ & $\begin{array}{l}\text { Experiencia } \\
\text { Valdemar en } \\
\text { familia }\end{array}$ & $\begin{array}{l}\text { Una actividad donde tanto } \\
\text { padres y niños aprenden } \\
\text { del mundo enológico. A } \\
\text { través de diferentes pruebas, } \\
\text { los niños deben ayudar } \\
\text { al Conde de Valdemar a } \\
\text { encontrar las uvas mágicas } \\
\text { que se han perdido en la } \\
\text { bodega. También degustan } \\
\text { mosto, tienen regalos y } \\
\text { disfrutan de una zona de } \\
\text { juegos. Al mismo tiempo, } \\
\text { los adultos degustan } 3 \text { vinos } \\
\text { maridados con un aperitivo. } \\
\text { Todo el recorrido se hace en } \\
\text { familia. }\end{array}$ & $\begin{array}{l}\text { https://enoturismo. } \\
\text { valdemar.es/ }\end{array}$ \\
\hline
\end{tabular}




\begin{tabular}{|c|c|c|c|c|}
\hline Bodega & $\begin{array}{c}\text { Destino } \\
\text { enoturístico }\end{array}$ & $\begin{array}{c}\text { Nombre de la } \\
\text { experiencia }\end{array}$ & Descripción & Web \\
\hline Bodegas Lecea & LA RIOJA & $\begin{array}{l}\text { Paseos en carro } \\
\text { de caballos }\end{array}$ & $\begin{array}{l}\text { Recorrido por los viñedos } \\
\text { de la familia Lecea en carro } \\
\text { de caballos, disfrutando } \\
\text { del paisaje de los parajes } \\
\text { riojanos. El paseo tiene } \\
\text { un recorrido de una } \\
\text { hora aproximadamente. } \\
\text { Posteriormente se visita la } \\
\text { bodega que tiene calados } \\
\text { excavados del S.XVI. }\end{array}$ & $\begin{array}{l}\text { http://www.bodegaslecea. } \\
\text { com/visitas-y- } \\
\text { enoturismo/\#experiencias }\end{array}$ \\
\hline Riojatrek & LA RIOJA & $\begin{array}{l}\text { Viticultor por un } \\
\text { día con niños }\end{array}$ & $\begin{array}{l}\text { Esta actividad está pensada } \\
\text { para que los adultos y } \\
\text { niños sean protagonistas de } \\
\text { una tradición ancestral: la } \\
\text { vitivinicultura (el cuidado } \\
\text { de la vid y la elaboración } \\
\text { del vino). De la mano de } \\
\text { un profesional se realizan } \\
\text { diferentes actividades en los } \\
\text { viñedos y la bodega. Los } \\
\text { niños aprenden aspectos } \\
\text { básicos del paisaje, la } \\
\text { vegetación, las uvas, } \\
\text { el mosto y el vino. Las } \\
\text { actividades son distintas } \\
\text { según la época del año. } \\
\text { Se incluye un aperitivo } \\
\text { con productos riojanos y } \\
\text { aprender a beber vino en } \\
\text { bota (mosto para los niños). } \\
\text { Los niños se encargan de los } \\
\text { experimentos en la bodega } \\
\text { que ayudan a comprender } \\
\text { la fermentación del vino. } \\
\text { También se visita la bodega } \\
\text { familiar tradicional, en } \\
\text { cuya cueva del s. XVI los } \\
\text { niños escuchan un cuento } \\
\text { relacionado con el vino. Y } \\
\text { finalmente, la familia elige } \\
\text { un vino que embotellan, } \\
\text { encorchan y etiquetan y se } \\
\text { llevan de recuerdo. }\end{array}$ & $\begin{array}{l}\text { https://www.riojatrek. } \\
\text { com/turismo-del-vino/ } \\
\text { actividades-para-familias- } \\
\text { con-ninos/ }\end{array}$ \\
\hline $\begin{array}{l}\text { Bodegas Franco- } \\
\text { Españolas }\end{array}$ & LA RIOJA & $\begin{array}{l}\text { Visita }+ \text { cata }+ \\
\text { aperitivo (con } \\
\text { guardería) }\end{array}$ & $\begin{array}{l}\text { Visita a la bodega para } \\
\text { conocer de la elaboración } \\
\text { del vino y su arquitectura } \\
\text { que se mantiene desde } \\
\text { 1890. Los más pequeños (de } \\
2 \text { a } 10 \text { años) pueden conocer } \\
\text { la cultura del vino con las } \\
\text { actividades de su ludoteca } \\
\text { (guardería tematizada). }\end{array}$ & $\begin{array}{l}\text { https://www. } \\
\text { francoespanolas.com/ } \\
\text { visitas/\# }\end{array}$ \\
\hline
\end{tabular}




\begin{tabular}{|c|c|c|c|c|}
\hline Bodega & $\begin{array}{c}\text { Destino } \\
\text { enoturístico }\end{array}$ & $\begin{array}{c}\text { Nombre de la } \\
\text { experiencia }\end{array}$ & Descripción & Web \\
\hline $\begin{array}{l}\text { Compañía Vinícola del } \\
\text { Norte de España }\end{array}$ & LA RIOJA & $\begin{array}{l}\text { Actividades } \\
\text { infantiles }\end{array}$ & $\begin{array}{l}\text { La bodega ofrece servicios } \\
\text { de ludoteca, creatividad } \\
\text { infantil y Viñart, un taller } \\
\text { de creatividad especial, } \\
\text { destinado a grupos de niños } \\
\text { de } 3 \text { y } 12 \text { años. Es una } \\
\text { propuesta de actividades } \\
\text { que giran en torno al mundo } \\
\text { del vino y de sus bodegas. } \\
\text { Incluye cuentacuentos, } \\
\text { creatividad, gastronomía, } \\
\text { juegos y música. Mientras, } \\
\text { los padres realizan la visita } \\
\text { a la bodega. }\end{array}$ & $\begin{array}{l}\text { http://www.visitascvne. } \\
\text { com/es/ }\end{array}$ \\
\hline Ilurce & LA RIOJA & $\begin{array}{l}\text { Ilurce y sus } \\
\text { niños }\end{array}$ & $\begin{array}{l}\text { Su actividad enoturística } \\
\text { más especial y exitosa, } \\
\text { dónde sus niños de la } \\
\text { quinta generación son } \\
\text { los encargados de guiar } \\
\text { a los niños visitantes } \\
\text { en el recorrido por la } \\
\text { bodega, pero de forma } \\
\text { más divertida, con juegos, } \\
\text { actividades, adivinanzas, } \\
\text { etc. }\end{array}$ & $\begin{array}{l}\text { http://www.ilurce. } \\
\text { com/enoturismo-rioja/ } \\
\text { actividades-especiales/ }\end{array}$ \\
\hline Ontañon & LA RIOJA & $\begin{array}{l}\text { Folos El } \\
\text { Centauro } \\
\text { Ontañón }\end{array}$ & $\begin{array}{l}\text { Experiencia en la que los } \\
\text { niños disfrutan con los } \\
\text { adultos de todo lo que } \\
\text { ofrece el mundo alrededor } \\
\text { del vino: arte, naturaleza, } \\
\text { mitología, ciencia, etc. Se } \\
\text { comparte con los niños } \\
\text { los secretos de un culto } \\
\text { ancestral. Incluye recorrido } \\
\text { bodega y winebar La } \\
\text { Sacristía, cata de } 3 \text { vinos } \\
\text { y } 2 \text { tapas para adulto, y } 2 \\
\text { mostos y tapas para los } \\
\text { niños. }\end{array}$ & $\begin{array}{l}\text { http://ontanon.es/reserva- } \\
\text { de-visitas-bodegas }\end{array}$ \\
\hline Finca Vistahermosa & LA RIOJA & $\begin{array}{l}\text { Actividades en } \\
\text { familia }\end{array}$ & $\begin{array}{l}\text { La actividad consiste en un } \\
\text { juego de pistas que están } \\
\text { escondidas en el viñedo, } \\
\text { donde se descubre la } \\
\text { naturaleza y biodiversidad } \\
\text { del viñedo, las plantas } \\
\text { típicas, el paisaje, los } \\
\text { animales, etc. Se consigue } \\
\text { un premio y se acompaña } \\
\text { de degustación de vinos y } \\
\text { mostos y pinchos a la brasa. } \\
\text { Incluye pringada de aceite } \\
\text { de oliva virgen del Valle de } \\
\text { Ocón. Se adapta a la época } \\
\text { del año. }\end{array}$ & $\begin{array}{l}\text { https://www. } \\
\text { fincavistahermosa.wine/ } \\
\text { actividades-en-familia/ }\end{array}$ \\
\hline
\end{tabular}




\begin{tabular}{|c|c|c|c|c|}
\hline Bodega & $\begin{array}{c}\text { Destino } \\
\text { enoturístico }\end{array}$ & $\begin{array}{c}\text { Nombre de la } \\
\text { experiencia }\end{array}$ & Descripción & Web \\
\hline ChâteauBardins & BURDEOS & $\begin{array}{l}\text { Atelier } \\
\text { "Dégustation en } \\
\text { famille" }\end{array}$ & $\begin{array}{l}\text { Taller sensorial interactivo } \\
\text { para familias que consiste } \\
\text { en adivinar aromas y } \\
\text { sabores por equipos } \\
\text { formados por adultos y } \\
\text { niños y a ciegas. Después } \\
\text { los niños realizan un juego } \\
\text { de pistas en las viñas } \\
\text { mientras los adultos hacen } \\
\text { una cata de vinos. Si los } \\
\text { niños son muy pequeños } \\
\text { hay una zona de libros, } \\
\text { juegos y colores cerca de } \\
\text { la zona donde los padres } \\
\text { hacen la degustación. }\end{array}$ & $\begin{array}{l}\text { https://www.degustation- } \\
\text { bordeaux.fr/portfolio/ } \\
\text { bordeaux-avec-les- } \\
\text { enfants/ }\end{array}$ \\
\hline Château Saint-Ahon & BURDEOS & $\begin{array}{l}\text { Les Jardins de } \\
\text { Mirabel }\end{array}$ & $\begin{array}{l}\text { Un recorrido libre alrededor } \\
\text { de las viñas y el bosque del } \\
\text { "Château Saint Ahon" que } \\
\text { cuenta con indicaciones } \\
\text { en paneles, un burro como } \\
\text { personaje e hilo conductor } \\
\text { de las explicaciones, y } \\
\text { códigos QR mediante los } \\
\text { cuales las familias pueden } \\
\text { descubrir información } \\
\text { sobre la naturaleza, las } \\
\text { viñas, la fauna y la flora de } \\
\text { este entorno. Este paseo } \\
\text { es accesible en carros de } \\
\text { bebé, las mascotas son } \\
\text { bienvenidas y hay una zona } \\
\text { de picnic y juegos. }\end{array}$ & $\begin{array}{l}\text { https://www.saintahon. } \\
\text { com/visites-activites/ } \\
\text { jardins-de-mirabel/ }\end{array}$ \\
\hline ChâteauSoutard & BURDEOS & $\begin{array}{l}\text { Parcours Nature } \\
\text { et/ ou location } \\
\text { de vélo }\end{array}$ & $\begin{array}{l}\text { Recorrido libre para hacer a } \\
\text { pie o en bicicleta alrededor } \\
\text { de los viñedos para } \\
\text { conocer la biodiversidad, } \\
\text { los métodos de trabajo } \\
\text { y el museo del "Château } \\
\text { Soutard", o incluso llegar } \\
\text { al pueblo. Se puede realizar } \\
\text { con familiar, con pareja o } \\
\text { amigos, con la ayuda de un } \\
\text { mapa y unos paneles. Las } \\
\text { bicicletas se pueden alquilar } \\
\text { en la bodega. }\end{array}$ & $\begin{array}{l}\text { http://www.chateau- } \\
\text { soutard.com/fr/ } \\
\text { oenotourisme.aspx }\end{array}$ \\
\hline
\end{tabular}




\begin{tabular}{|c|c|c|c|c|}
\hline Bodega & $\begin{array}{c}\text { Destino } \\
\text { enoturístico }\end{array}$ & $\begin{array}{c}\text { Nombre de la } \\
\text { experiencia }\end{array}$ & Descripción & Web \\
\hline ChâteauAgassac & BURDEOS & Jeu de piste & $\begin{array}{l}\text { Actividad para los niños } \\
\text { para realizar mientras los } \\
\text { padres descubren los vinos } \\
\text { y la historia del castillo. } \\
\text { La actividad consiste en } \\
\text { un juego de pistas que se } \\
\text { realiza con la ayuda de } \\
\text { un i-Pad que utiliza voz y } \\
\text { videos para guiar a los niños } \\
\text { en el castillo y les explica la } \\
\text { historia y los vinos de forma } \\
\text { original, y les formula } \\
\text { preguntas, sin olvidar nunca } \\
\text { el hilo conductor, la misión } \\
\text { de liberar la "Princesse } \\
\text { Etoile" que es prisionera } \\
\text { des de hace siglos en la } \\
\text { torre del castillo. }\end{array}$ & $\begin{array}{l}\text { https://www.agassac.com/ } \\
\text { oenotourisme/jeu-de-piste }\end{array}$ \\
\hline Château Le Crock & BURDEOS & Trésor Ô Crock & $\begin{array}{l}\text { Juego al estilo "caza del } \\
\text { tesoro" que utiliza un hilo } \\
\text { conductor, un mapa y } \\
\text { varias pistas para conseguir } \\
\text { una misión y que a la vez } \\
\text { permite a toda la familia } \\
\text { descubrir toda la propiedad. } \\
\text { La misión consiste en } \\
\text { recuperar la receta de los } \\
\text { vinos de la bodega que } \\
\text { ha robado el fantasma del } \\
\text { primer propietario. Mayores } \\
\text { y niños deberán resolver } \\
\text { enigmas para resolver la } \\
\text { misión. }\end{array}$ & $\begin{array}{l}\text { https://chateaulecrock.fr/ } \\
\text { visites-et-degustations/ }\end{array}$ \\
\hline $\begin{array}{l}\text { La Maison des Vins de } \\
\text { Cadillac }\end{array}$ & BURDEOS & $\begin{array}{l}\text { Les Jeux de } \\
\text { Raisin de la } \\
\text { Maison des Vins }\end{array}$ & $\begin{array}{l}\text { La Maison des vins de } \\
\text { Cadillac cuenta con un } \\
\text { espacio exterior de juegos } \\
\text { para niños y también de } \\
\text { una zona de picnic para } \\
\text { las familias. La zona } \\
\text { infantil contiene juegos } \\
\text { variados como puzles, cajas } \\
\text { misteriosas, enigmas, etc. } \\
\text { Están relacionados con } \\
\text { la elaboración del vino, } \\
\text { la viña, el patrimonio, las } \\
\text { estaciones, etc. También } \\
\text { hay algunos juegos más } \\
\text { deportivos. }\end{array}$ & $\begin{array}{l}\text { https://www. } \\
\text { maisondesvinsdecadillac. } \\
\text { com/les-jeux-de-raisin-de- } \\
\text { la-maison-des-vins/ }\end{array}$ \\
\hline $\begin{array}{l}\text { Château Monconseil } \\
\text { Gazin }\end{array}$ & BURDEOS & $\begin{array}{l}\text { Escape game } \\
\text { oenologique: } \\
\text { le trésor } \\
\text { Charlemagne }\end{array}$ & $\begin{array}{l}\text { Juego al estilo "Escape } \\
\text { room" dentro de la bodega, } \\
\text { relacionado con la historia } \\
\text { de Carlomagno, de la } \\
\text { bodega y de sus vinos. Este } \\
\text { juego combina elementos } \\
\text { de caza del tesoro, enigmas, } \\
\text { códigos y trabajo en equipo. }\end{array}$ & $\begin{array}{l}\text { https://www. } \\
\text { escapegameblaye.com/ }\end{array}$ \\
\hline
\end{tabular}




\begin{tabular}{|c|c|c|c|c|}
\hline Bodega & $\begin{array}{c}\text { Destino } \\
\text { enoturístico }\end{array}$ & $\begin{array}{c}\text { Nombre de la } \\
\text { experiencia }\end{array}$ & Descripción & Web \\
\hline Château Pas de l'Ane & BURDEOS & Escape Wine & $\begin{array}{l}\text { Juego al estilo "Escape } \\
\text { room" donde cerrados en } \\
\text { una sala de la bodega los } \\
\text { visitantes deberán encontrar } \\
\text { el secreto de la receta de } \\
\text { unos vinos que realizaba la } \\
\text { antigua propietaria Madame } \\
\text { De Lafarce. }\end{array}$ & http://www.oenanim.fr/ \\
\hline Château de Portets & BURDEOS & $\begin{array}{l}\text { Expérience } \\
\text { Famille: Sur la } \\
\text { piste du Château } \\
\text { de Portets... }\end{array}$ & $\begin{array}{l}\text { Juego de pistas para } \\
\text { descubrir de forma libre la } \\
\text { historia del "château" y la } \\
\text { elaboración de su vino. El } \\
\text { juego se finaliza con una } \\
\text { degustación de mosto y la } \\
\text { obtención de un diploma. }\end{array}$ & $\begin{array}{l}\text { https://www. } \\
\text { chateaudeportets.fr/les- } \\
\text { visites }\end{array}$ \\
\hline ChâteauVillemaurine & BURDEOS & $\begin{array}{l}\text { Visite } \\
\text { patrimoine } \\
\text { du Chateau } \\
\text { Villemaurine }\end{array}$ & $\begin{array}{l}\text { Situado en una zona de } \\
\text { suelo arcilloso-calcáreo, } \\
\text { esta bodega es única con } \\
\text { unos sótanos especiales. } \\
\text { Acompañado de un guía } \\
\text { los visitantes descubrirán } \\
\text { los pasadizos subterráneos. } \\
\text { Cuentan también con una } \\
\text { animación de sonido y } \\
\text { luces que acompañan la } \\
\text { explicación sobre la bodega } \\
\text { y el pueblo de Saint- } \\
\text { Émilion. }\end{array}$ & $\begin{array}{l}\text { https://www.villemaurine. } \\
\text { com/index.php/fr/visiter- } \\
\text { villemaurine/visite- } \\
\text { patrimoine }\end{array}$ \\
\hline Château de Cerons & BURDEOS & $\begin{array}{l}\text { Pique-nique } \\
\text { dans le Parc }\end{array}$ & $\begin{array}{l}\text { La bodega ofrece cestas } \\
\text { para realizar picnic con } \\
\text { una selección de productos } \\
\text { locales y sus vinos. Tienen } \\
\text { una zona especial para } \\
\text { realizar picnics en el } \\
\text { entorno de la propiedad. } \\
\text { Los visitantes podrán } \\
\text { también añadir productos de } \\
\text { la tienda. }\end{array}$ & $\begin{array}{l}\text { http://www. } \\
\text { chateaudecerons.fr/ } \\
\text { visites-receptions-vins-de- } \\
\text { graves/ }\end{array}$ \\
\hline Castello di Amorosa & $\begin{array}{l}\text { NAPA } \\
\text { VALLEY }\end{array}$ & $\begin{array}{l}\text { General } \\
\text { Admission \& } \\
\text { Wine Tasting }\end{array}$ & $\begin{array}{l}\text { Visita guiada o libre al } \\
\text { Castillo, una réplica de un } \\
\text { castillo italiano de época } \\
\text { medieval e instalaciones } \\
\text { bodega con degustación de } \\
\text { vinos para los padres y de } \\
\text { mosto para los niños. }\end{array}$ & $\begin{array}{l}\text { https://castellodiamorosa. } \\
\text { com/experiences/ }\end{array}$ \\
\hline
\end{tabular}




\begin{tabular}{|c|c|c|c|c|}
\hline Bodega & $\begin{array}{c}\text { Destino } \\
\text { enoturístico }\end{array}$ & $\begin{array}{c}\text { Nombre de la } \\
\text { experiencia }\end{array}$ & Descripción & Web \\
\hline Raymond winery & $\begin{array}{l}\text { NAPA } \\
\text { VALLEY }\end{array}$ & $\begin{array}{l}\text { Theater of } \\
\text { Nature }\end{array}$ & $\begin{array}{l}\text { Experiencia que ofrecen } \\
\text { en la bodega Raymond. } \\
\text { Se llama "el Teatro de } \\
\text { la Naturaleza" y es una } \\
\text { exhibición educacional } \\
\text { sobre la agricultura } \\
\text { biodinámica en Napa } \\
\text { Valley. Muestra como todos } \\
\text { los "actores" juegan un } \\
\text { papel muy importante en la } \\
\text { elaboración del vino. Como } \\
\text { si fuera un espectáculo de } \\
\text { teatro, el recorrido está } \\
\text { dividido en cinco actos, } \\
\text { cada uno de ellos dedicado } \\
\text { a un componente particular } \\
\text { de la naturaleza. }\end{array}$ & $\begin{array}{l}\text { https://raymondvineyards. } \\
\text { com/experience/theater- } \\
\text { of-nature/ }\end{array}$ \\
\hline Robert Mondavicellar & $\begin{array}{l}\text { NAPA } \\
\text { VALLEY }\end{array}$ & $\begin{array}{l}\text { Art Collection } \\
\text { Tour }(+13)\end{array}$ & $\begin{array}{l}\text { Bodega con una colección } \\
\text { de arte que los visitantes } \\
\text { mayores de } 13 \text { años pueden } \\
\text { admirar. }\end{array}$ & $\begin{array}{l}\text { https://www. } \\
\text { robertmondaviwinery. } \\
\text { com/art-collection-tour }\end{array}$ \\
\hline SterlingVineydards & $\begin{array}{l}\text { NAPA } \\
\text { VALLEY }\end{array}$ & $\begin{array}{l}\text { Signature } \\
\text { Winery Tour/ } \\
\text { Aerial Tram }\end{array}$ & $\begin{array}{l}\text { Visita que incluye paseo } \\
\text { en teleférico con vistas } \\
\text { panorámicas a los viñedos. }\end{array}$ & $\begin{array}{l}\text { https://www. } \\
\text { sterlingvineyards.com/en- } \\
\text { us/visit/tastings }\end{array}$ \\
\hline GrgichHillsEstates & $\begin{array}{l}\text { NAPA } \\
\text { VALLEY }\end{array}$ & Grape Stomping & $\begin{array}{l}\text { Actividad de pisada de uva } \\
\text { en la época de vendimia, } \\
\text { incluye también degustación } \\
\text { de vino para los adultos. }\end{array}$ & $\begin{array}{l}\text { https://www.grgich.com/ } \\
\text { visit-us/tours-tastings/ }\end{array}$ \\
\hline Francis Ford Coppola & SONOMA & $\begin{array}{l}\text { Ford Coppola } \\
\text { museum }\end{array}$ & $\begin{array}{l}\text { La bodega Francis Ford } \\
\text { Coppola se ha convertido } \\
\text { en una especie de resort } \\
\text { que dispone de piscinas } \\
\text { para que los niños y padres } \\
\text { puedan bañarse, una } \\
\text { librería para niños, zona } \\
\text { de juegos, museo, etc. Los } \\
\text { padres pueden pedir vinos y } \\
\text { comida en la piscina. Otro } \\
\text { de sus servicios estrella } \\
\text { es el museo sobre las } \\
\text { películas de Coppola como } \\
\text { El Padrino y Drácula. En } \\
\text { alguna de las visitas guiadas } \\
\text { y experiencias que ofrecen } \\
\text { los niños son bienvenidos. }\end{array}$ & $\begin{array}{l}\text { https://www. } \\
\text { francisfordcoppolawinery. } \\
\text { com/en/visit }\end{array}$ \\
\hline Preston Farm\&Winery & SONOMA & $\begin{array}{l}\text { Self-guided } \\
\text { walking tour of } \\
\text { the farm }\end{array}$ & $\begin{array}{l}\text { La bodega dispone de una } \\
\text { granja con animales, zona } \\
\text { de picnic, productos locales, } \\
\text { un entorno ideal para las } \\
\text { familias. La visita guiada no } \\
\text { permite niños, pero ofrecen } \\
\text { una visita libre a la granja } \\
\text { para las familias. }\end{array}$ & $\begin{array}{l}\text { https:// } \\
\text { prestonfarmandwinery. } \\
\text { com/visit }\end{array}$ \\
\hline
\end{tabular}




\begin{tabular}{|c|c|c|c|c|}
\hline Bodega & $\begin{array}{c}\text { Destino } \\
\text { enoturístico }\end{array}$ & $\begin{array}{c}\text { Nombre de la } \\
\text { experiencia }\end{array}$ & Descripción & Web \\
\hline LarsonFamilyWinery & SONOMA & Bring a Picnic & $\begin{array}{l}\text { Esta bodega ofrece mesas } \\
\text { de picnic para realizar } \\
\text { degustaciones, comer y } \\
\text { conocer su propiedad. Los } \\
\text { niños pueden disfrutar } \\
\text { también de zonas de juegos } \\
\text { para ellos. }\end{array}$ & $\begin{array}{l}\text { http://www. } \\
\text { larsonfamilywinery.com// } \\
\text { visit.html }\end{array}$ \\
\hline LandmarkVineyards & SONOMA & $\begin{array}{l}\text { Horse- } \\
\text { drawncarriage } \\
\text { tours }\end{array}$ & $\begin{array}{l}\text { La bodega ofrece a parte } \\
\text { de las degustaciones y } \\
\text { visitas guiadas, un paseo en } \\
\text { caballo donde se explica las } \\
\text { técnicas de la elaboración } \\
\text { del vino y la historia de } \\
\text { Sonoma. No hace falta } \\
\text { reservar. También disponen } \\
\text { de zonas de picnic. }\end{array}$ & $\begin{array}{l}\text { https://www. } \\
\text { landmarkwine.com/visit- } \\
\text { landmark/tasting-tour- } \\
\text { sonoma-valley.html }\end{array}$ \\
\hline BenzigerFamilyWinery & SONOMA & $\begin{array}{l}\text { Biodynamic } \\
\text { Vineyard Tram } \\
\text { Tour }\end{array}$ & $\begin{array}{l}\text { Paseo en trenecito por los } \\
\text { viñedos donde aprenderán } \\
\text { las prácticas agrícolas } \\
\text { de la propiedad y las } \\
\text { características de los vinos. }\end{array}$ & $\begin{array}{l}\text { https://www.benziger. } \\
\text { com/experience-our- } \\
\text { winery/ }\end{array}$ \\
\hline Buena Vista Winery & SONOMA & $\begin{array}{l}\text { Historic Wine } \\
\text { Museum Tour } \\
\text { and Tasting }\end{array}$ & $\begin{array}{l}\text { Museo que combina } \\
\text { herramientas e historia con } \\
\text { elementos audiovisuales } \\
\text { como luz, sonido y un } \\
\text { espectáculo visual. Después } \\
\text { de la visita al museo, los } \\
\text { padres realizarán una } \\
\text { degustación. }\end{array}$ & $\begin{array}{l}\text { https://buenavistawinery. } \\
\text { com/visit/ }\end{array}$ \\
\hline Cornerstone Sonoma & SONOMA & $\begin{array}{l}\text { Cornerstone } \\
\text { gardens }\end{array}$ & $\begin{array}{l}\text { La bodega dispone de unos } \\
\text { jardines con esculturas de } \\
\text { artistas internacionales. } \\
\text { Algunas de estas esculturas } \\
\text { son interactivas y permiten } \\
\text { a los niños escalar y jugar } \\
\text { con el arte. El acceso es } \\
\text { público y gratuito. Se } \\
\text { puede reservar un tour } \\
\text { privado en los jardines o } \\
\text { complementarlo con un } \\
\text { picnic, el restaurante o } \\
\text { degustación de vinos. }\end{array}$ & $\begin{array}{l}\text { http://www. } \\
\text { cornerstonesonoma.com/ } \\
\text { gardens }\end{array}$ \\
\hline
\end{tabular}

\subsection{Análisis cuantitativo y cualitativo de las empresas bodegueras}

Para el análisis de la información contenida en las webs de las empresas bodegueras se han obtenido el conjunto de los indicadores más utilizados y se han desglosado en cinco grupos, tal y como se puede observar en la tabla 3. En el primer grupo se analiza la experiencia compartida versus separada, es decir, sirve para conocer el destinatario de las experiencias, diferenciando entre si van dirigidas a niños y adultos por separado o de forma compartida, así como si existe un precio especial para niños. El segundo grupo está relacionado con la tipología de la experiencia o actividad, distinguiendo entre; elaboración 
del vino, cultura, deporte, naturaleza, gastronómica o de ocio. El tercer grupo aglutina aspectos relacionados con la actividad como son; si la actividad es guiada o no, si se programa de forma regular y en que idiomas se realiza. El cuarto grupo de indicadores se refiere a los recursos utilizados para llevar a cabo la experiencia enoturística; recursos del interior de la bodega, exteriores, la existencia de infraestructuras adaptadas para los niños y recursos tecnológicos. Finalmente, el último indicador se refiere a la posibilidad de realizar la reserva y venta en la modalidad on line.

\section{Tabla 3 \\ DISTRIBUCIÓN Y NÚMERO DE INDICADORES SELECCIONADOS}

\begin{tabular}{ll}
\hline GRUPO 1 & Experiencia compartida versus separada \\
\hline & Niños y adultos por separado \\
& Compartida adultos y niños \\
& Precio especial niños \\
\hline GRUPO 2 & Tipología de experiencias \\
& Elaboración del vino \\
& Cultura \\
& Deporte \\
& Naturaleza \\
& Gastronomía \\
& Otras actividades \\
\hline GRUPO 3 & Experiencia guiada versus por libre \\
& Libre o autoguiado \\
& Guiada \\
& Programación regular \\
& Idiomas \\
\hline GRUPO 4 & Recursos utilizados en las experiencias \\
& Interior de las instalaciones \\
& Exterior \\
& Recursos, servicios o infraestructuras adaptadas a los niños \\
& Recursos tecnológicos \\
\hline GRUPO 5 & Venta online \\
\hline & Venta online \\
\hline
\end{tabular}

A continuación, en la figura 3 , se indican los resultados más relevantes que se han obtenido a partir del análisis de los contenidos webs.

En primer lugar, de las 57 experiencias analizadas, 12 ofrecen una actividad exclusiva para los niños o una parte de la visita se realiza de forma separada, los padres por un lado y los niños por otro. También se han observado situaciones en las que durante la degustación de vinos que realizan los padres, a los niños se les ofrece realizar un taller o actividad con un monitor. En otros casos, la visita o taller es exclusivo para los niños y los padres pueden realizar una de las visitas o actividades regulares de la bodega. De este 
análisis, se identifican 6 experiencias que combinan una parte de la experiencia compartida y otra parte separados. Sin embargo, la gran mayoría de propuestas están enfocadas para ser compartidas por padres u otros miembros de la familia y los niños conjuntamente. En total son 51 experiencias las que se engloban en este tipo de propuesta. En esta categoría se observan experiencias en las que se fomenta la participación entre familiares y otras más pasivas.

Para las familias el factor precio es relevante y, es por eso que, éste es un indicador a estudiar en el análisis de la creación de experiencias dirigidas a este segmento de mercado, en concreto, 36 de las experiencias realizan un precio especial para los niños. Las bodegas asumen así que el público más atraído por la bodega es el adulto y que éste espera que la actividad para al niño tenga un coste menor. Los precios varían bastante en función del tipo de actividad, la duración y los recursos utilizados, pero en general están entre 5 y $15 €$. También se observa que muchas bodegas ofrecen precios distintos según las edades de los niños, si son más pequeños el precio es menor. En muchos casos, los menores de 5 años son gratuitos. Por último, indicar que, en ocasiones, la información relativa al precio no estaba disponible.

\section{Figura 3 \\ GRADO DE CUMPLIMIENTO DE LOS INDICADORES}

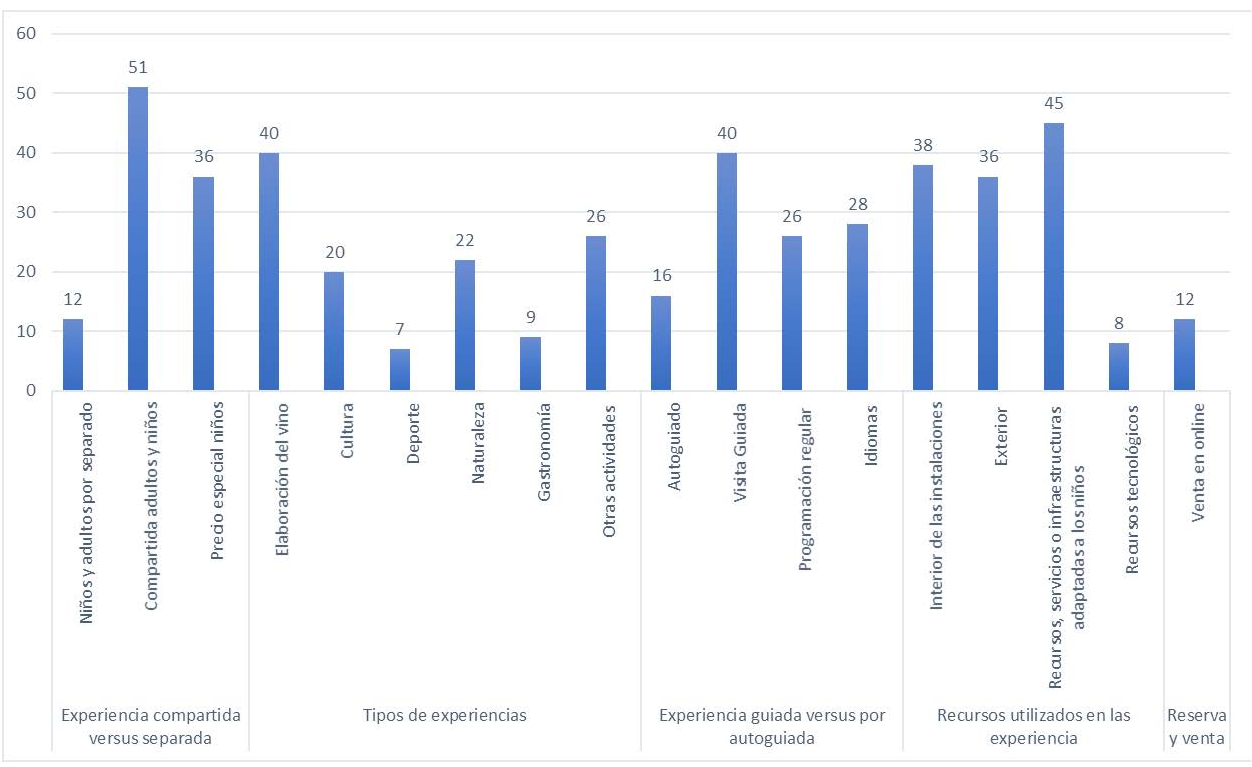

En cuanto al segundo grupo, la tipología de la experiencia, hay que indicar que una misma experiencia puede ser considerada de varios tipos según si combina diferentes elementos o está asociada a diferentes productos turísticos. En este sentido, de las 57 experiencias analizadas, 40 incluyen contenidos relacionados con el proceso de elaboración del 
vino, 20 incluyen componentes relacionados con la cultura, 7 proponen alguna actividad deportiva, 22 fomentan el contacto con la naturaleza, 9 incluyen elementos gastronómicos (más allá del vino, el mosto o las uvas) y 26 contienen actividades o servicios de ocio.

Del presente análisis se observa que las bodegas están aprovechando la combinación de diferentes productos turísticos para proponer experiencias de enoturismo familiar variadas y más atractivas. Las experiencias que tienen algún componente cultural suelen estar asociadas a conocer la historia y el patrimonio de la bodega, la cultura de la zona en que están ubicadas o bien incluyen la visita a algún museo. En algunos casos, se pueden observar otras propuestas más alternativas como la realización de un taller de circo (Ferré i Catasús) o la organización de un festival de música (Bodegas Franco-Españolas). Y, a veces, únicamente se aprovecha algún elemento cultural para ambientar la actividad o crear un hilo conductor.

En cuanto a las experiencias de naturaleza, éstas se dividen principalmente en visitas y actividades que se realizan íntegramente o en parte en los viñedos de la propiedad, en otros espacios exteriores de la bodega como jardines o zonas de picnic o en espacios naturales cercanos a la bodega (ej. Vía Verde en la experiencia de Cal Menescal o el río Ebro en la propuesta de Vins Suñer). Las viñas son un recurso ampliamente utilizado tanto para conocer las vides y el proceso de elaboración del vino, como espacio de juego en el cual se pueden realizar actividades físicas y como paisaje a admirar.

Las actividades deportivas más populares realizadas entre viñas analizadas son el senderismo o trekking y el cicloturismo (tanto con bicicletas convencionales como eléctricas).

El término ocio es muy amplio y podría englobar todas las experiencias, pero en este caso se ha atribuido esta característica a todas aquellas experiencias que buscan el entretenimiento y no pueden englobarse en las otras tipologías. En esta categoría se encuentran los talleres de manualidades y yincanas, entre otros.

En lo referente al tercer grupo de indicadores, la mayor parte de las experiencias identificadas son guiadas o conducidas por un profesional de la bodega (en 45 de los casos). Sin embargo, en 16 de ellas todas estas experiencias se realizan por libre y 40 son guiadas. Algunas de las experiencias se ofrecen, tanto por libre como guiadas, como por ejemplo el Walk \& Wine de Mas Vicenç. Además, la duración varía según el tipo y contenido de la experiencia, pero en general está entre una y tres horas. Los idiomas disponibles suelen ser los locales y, en algún caso, el inglés como la lengua internacional.

En cuanto a los recursos más utilizados, del total de experiencias identificadas, 38 se realizan en espacios del interior de las instalaciones, 36 en espacios exteriores y 18 combina ambos. Así, se observa que hay un volumen bastante igualitario tanto de propuesta de interior como de exterior. El término interior en este análisis se refiere básicamente a la bodega, aunque en algún caso también a otros espacios adyacentes como salas de talleres, museos o centros de interpretación. Y en cuanto al indicador exterior, éste coincide con las experiencias de naturaleza que engloba las actividades en las viñas, jardines u otras instalaciones exteriores de las propiedades de las bodegas o entornos naturales cercanos a las bodegas.

En función de las innovaciones basadas en la introducción o con el uso de elementos tecnológicos, únicamente se identifican 8 experiencias. Los recursos tecnológicos observa- 
dos son variados: aplicaciones móviles, iPad, 4D, códigos $\mathrm{QR}$, audiovisuales y animación de luces y sonidos.

Entre los recursos adaptados a los niños que se utilizan en estas experiencias dirigidas a las familias destacan; los juegos, las yincanas (pruebas y pistas), las manualidades, los talleres sensoriales, las visitas teatralizadas, la degustación de mosto, el lenguaje, entre otros.

También se puede subrayar, a parte de la experiencia familiar programada, algunas bodegas prestan atención en otros detalles y servicios que pueden satisfacer las necesidades de las familias en una bodega. Algunos ejemplos son la accesibilidad (rampas, baños adaptados, etc.), zonas de juego o ludotecas, parques infantiles exteriores, zonas de picnic, piscina o vigilancia, entre otros.

La información relativa a la difusión de la innovación, la reserva y la venta como factores principales en la comercialización de la experiencia, indica una carencia en la comunicación de la información e innovación en la venta de las experiencias. De las 57 propuestas, se considera que solamente 19 ofrecen una información completa y detallada en su página web. En 31 casos éstas pueden ser reservadas mediante formulario desde la misma página web de la bodega, pero solo en 12 casos es posible pagarlas. Por último, la mayor parte de las bodegas tienen perfiles en las principales redes sociales. Este indicador ha sido identificado en 47 de los casos.

A continuación, en la figura 4 , se ha representado gráficamente el grado de cumplimiento de los indicadores analizados, medido como el porcentaje de respuesta afirmativa al grupo de indicadores propuesto. Así, el indicador con menor grado de cumplimiento es la venta online (18\%) y el grupo de indicadores con un mayor grado es el relacionado con la experiencia compartida versus separada (36\%).

\section{Figura 4}

PORCENTAJE DE CUMPLIMENTO RESPECTO AL TOTAL DE LOS INDICADORES

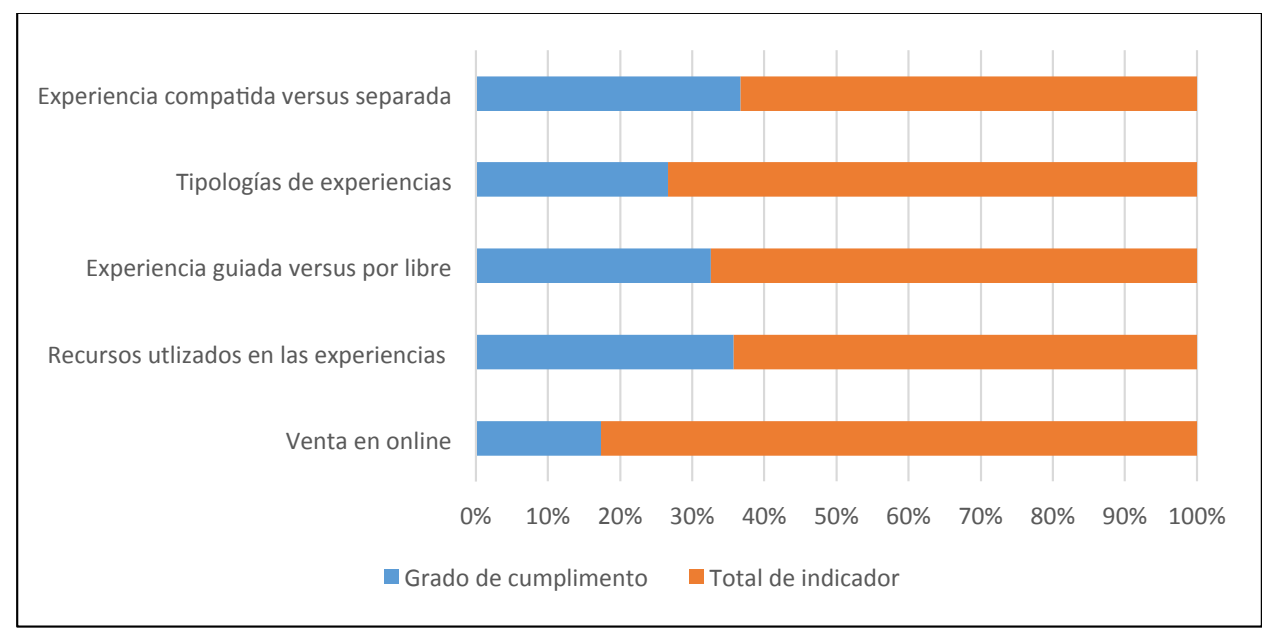


Finalmente, como resultado de este estudio, se puede afirmar que en todos los destinos turísticos seleccionados se presta una atención especial a las familias ya sea con el contenido de las visitas o actividades, con el precio o la adaptación del espacio. Las visitas y actividades propuestas están normalmente relacionadas con el proceso de elaboración del vino y su cultura. En todos los destinos se observan tanto experiencias realizadas en el interior como en el exterior, aunque es en Burdeos y Napa Valley - Sonoma se detectan una mayor apuesta por ofrecer servicios al exterior. También es frecuente la oferta de servicios basados en el juego cuando se piensa en familias, aunque en algunos lugares se ha apostado más por crear zonas de juegos y, en otros, por ofrecer juegos con pistas y pruebas. Las yincanas se observan tanto en Cataluña, como La Rioja y Burdeos. Por último, en general se detectan pocas innovaciones tecnológicas, falta de información y de comunicación y venta en línea de las experiencias de enoturismo familiar.

Como diferencias principales a destacar, solo en Cataluña se identifican visitas teatralizadas para familias. También es la región donde se observan más actividades deportivas que utilizan los viñedos y otros paisajes de la zona como propuesta de valor. En Cataluña se ha identificado dos experiencias que se ha basado en una innovación tecnológica (Orient-tast de EstolVerd y audiovisual en Freixenet).

En La Rioja una innovación destacable son las ludotecas y los talleres adaptados a los menores. También destacan las yincanas, la apuesta por la accesibilidad de las instalaciones y la combinación con la gastronomía como propuesta de valor. En la Rioja se han detectado dos experiencias basadas en innovaciones tecnológicas (experiencia 4D en Villa Lucía y juegos interactivos en el Museo de la Fundación Vivanco).

En Burdeos se presta mucha atención a las actividades por libre dirigidas a familias y espacios infantiles en el exterior. De hecho, se han identificado más experiencias que suceden en espacios al exterior que en el interior, entre las cuales hay que destacar las zonas de picnic y áreas de juegos. Se han identificado tres innovaciones tecnológicas (códigos QR en los Jardins Maribel, yincana con iPad en Château Agassac y animación de sonido y luces en el Château Villemaurine).

En Napa Valley y Sonoma, las bodegas no son solo espacios dedicados a la producción del vino sino que conviven con otros espacios de ocio o rurales (por ejemplo, granjas, piscina, jardines, etc.). En este caso, ponen en valor su paisaje y apuestan más por las actividades al exterior. La naturaleza y el ocio son ingredientes importantes en las experiencias con familias, entre las que hay que destacar las zonas de picnics y las áreas de juegos para niños.

Por otra parte, de las entrevistas y visitas realizadas a las bodegas (ver tabla 1 del epígrafe de metodología) también se desprende que la propuesta de valor de las innovaciones analizadas se basa, en todos los casos, en ofrecer una atención especial a las familias, pero especialmente a los menores. En casi todos los casos, se insiste en que, si los niños están contentos y disfrutan de la experiencia, los padres también.

En algunas ocasiones, la apuesta por el segmento familiar busca diferenciarse de otras bodegas que ofrecen enoturismo. En definitiva, identifican las familias que visitan bodegas como un segmento de mercado no cubierto y por tanto una oportunidad de negocio. Para otras en cambio, las familias no son su público objetivo principal y la propuesta a las familias es un servicio secundario o complementario a las otras visitas. En este caso, 
algunas coinciden en que si ofrecen una visita específica para las familias, las visitas estándar funcionan mejor porque a veces los niños pueden dificultar el disfrute de las mismas.

Por lo general, las experiencias dirigidas a las familias no son rentables a nivel económico para las bodegas ya que la contratación de guías o monitores tienen un coste elevado. Sin embargo, la mayoría afirma obtener efectos indirectos beneficiosos como son una mayor demanda, la mejora de su imagen y posicionamiento, y la venta de vinos.

En menos de la mitad de los casos, combinan la visita familiar con algún otro servicio turístico externo. Y, en lo relativo a la difusión y comercialización, la mayoría basan su estrategia de comunicación en su página web. En algunos casos, se comercializan también a través de plataformas especializadas en familias o mediante los hoteles de su zona. Por último, como aspecto muy relevante de las entrevistas hay que destacar que existe una escasa colaboración entre bodegas y establecimientos turísticos.

\section{CONCLUSIONES}

El presente estudio demuestra el potencial que existe alrededor del nicho de mercado de las familias en enoturismo, así como el creciente interés por las bodegas en captarlo. De hecho, como conclusión principal del estudio, se observa una gran variedad en la generación de experiencias de enoturismo familiar por parte de las bodegas españolas, tratándose de una actividad económica incipiente y una buena oportunidad de negocio. De este modo, un producto enoturístico es el resultado de la combinación de recursos enoturísticos, servicios, instalaciones y atractivos. Entre los recursos enoturísticos más utilizados en las propuestas analizadas están las bodegas, la elaboración del vino, las viñas y la cultura del vino.

Las bodegas analizadas han visto en el segmento familiar una oportunidad de diferenciación y diversificación de su oferta. De la misma forma, son una vía de promoción ya que de acuerdo con las entrevistas realizadas, en muchos casos, se ha detectado que las familias o algunos miembros de la misma repiten con otros amigos o vuelven a consumir otra experiencia sin niños.

En cuanto al producto, un factor fundamental para la especialización es la adaptación a las necesidades de las familias, principalmente mediante atenciones a los niños ya que, si los niños tienen una buena experiencia, los padres también la tienen. Según los resultados, los elementos más comunes de las experiencias identificadas son el juego, las experiencias sensoriales y participativas, la cultura del vino, la interacción y el uso de elementos adaptados a los niños (lenguaje, materiales gráficos, espacios, etc.).

La evolución del mercado turístico por un consumo de productos que impliquen una mayor participación del turista es también palpable en el enoturismo y en el segmento de las familias. De hecho, los niños requieren actividades más dinámicas y en las que puedan ser protagonistas. En el estudio se muestra una gran cantidad de experiencias donde hay una participación activa del cliente. Los talleres de manualidades, las actividades de vendimia y los paseos en bicicleta son algunos ejemplos.

Debido a que es un segmento incipiente y tratándose del sector servicios, las innovaciones son más bien de tipo incremental y no presentan un grado elevado de innovación. En este sentido, la mejora continua se convierte en una fase imprescindible del proceso de 
innovación para conseguir su éxito. Sin embargo, el potencial innovador es elevado ya que se detecta en la mayoría un aumento de la demanda y beneficios económicos indirectos (mejora de la imagen de la bodega, mayor demanda e incremento de la venta de vino).

También hay que indicar que otros aspectos como la mayor profesionalización del sector y el uso de herramientas basadas en el conocimiento (investigaciones de mercado, análisis de la competencia o asesoramiento especializado) serán claves para superar los obstáculos más comunes.

Además, se han observado pocas innovaciones tecnológicas, pero aquellas identificadas han sido muy bien aceptadas por los turistas. Así, se puede afirmar que la implementación de tecnología puede ser un valor añadido en la creación de nuevas experiencias, sobretodo en aspectos que a día de hoy son deficientes como la comunicación, la reserva y la venta de las experiencias. En definitiva, se demuestra que la creación de experiencias de enoturismo familiar es un modelo innovador que ofrece beneficios a las bodegas y, en consecuencia, a los destinos enoturísticos.

Por último, señalar que el presente estudio se ha circunscrito a un número limitado de bodegas, por lo que sería interesante extender dicho estudio a otras empresas de otros territorios tanto nacionales como internacionales. Por otra parte, los indicadores contemplados en este análisis no son los únicos, existen otros atractivos y posibles mejoras e innovaciones que servirán para satisfacer mejor la demanda del segmento familiar.

Declaración responsable: Los autores declaran que no existe ningún conflicto de interés en relación a la publicación de este artículo. Igualmente, los autores comunican que todas las partes del mencionado artículo de investigación, incluyendo las correcciones realizadas a requerimiento de la revista, han sido elaborado de forma cooperativa. Es decir, los tres autores han realizado conjuntamente el diseño general del artículo, la discusión de resultados, la recopilación de información a partir de fuentes primarias y secundarias, la revisión bibliográfica y la redacción del mismo.

\section{BIBLIOGRAFÍA}

AGENCIA CATALANA DE TURISMO (ACT) (2019): Requisitos sello Natura y montaña en familia. Generalitat de Catalunya. Recuperado el 2 de febrero de 2020:http://act. gencat.cat/wpcontent/uploads/2016/03/Requisits_Segell_Natura_Muntanya_Familia. pdf.

AGENCIA CATALANA DE TURISMO (2019): Conclusiones I Congreso Internacional de Turismo Familiar. Documento de trabajo interno del Patronat de Turisme de la Diputación de Tarragona (No publicado):

ARAÚJO, N. (2015): «De la economía de experiencias al turismo experiencial. Las series de ficción como creadoras de experiencias e inductoras a la visita de destinos turísticos». PASOS. Revista de Turismo y Patrimonio Cultural, vol. 13 (4), pp. 959-964.

ACEVIN y RUTAS VINO DE ESPAÑA (2017): Análisis de la Demanda Turística Rutas del Vino de España 2016-2017. Recuperado el 15 de diciembre de https://www.wineroutesofspain.com/bd/archivos/archivo784.pdf 
ANTON, S. y DURO, A. (2009): Competitividad y sistemas de innovación territorial en turismo. Cátedra Innova - Working Papers Innova 2009-1. Recuperado de http://www. urv.cat/media/upload/arxius/catedra-innovacio-empresarial/wp_1.pdf

ASOCIACIÓN ESPAÑOLA DE CIUDADES DEL VINO (ACEVIN): (2018a): Informe de visitantes a bodegas y museos del vino asociados a las Rutas del Vino de España 2017. Recuperado el 20 de enero de 2020 de https://www.wineroutesofspain.com/bd/ archivos/archivo873.pdf

ASOCIACIÓN ESPAÑOLA DE CIUDADES DEL VINO (ACEVIN): (2028b): Análisis de la Demanda Turística Rutas del Vino de España 2017-2018. Recuperado el 20 de enero de 2020 de: https://www.wineroutesofspain.com/bd/archivos/ archivo916.pdf.

ASOCIACIÓN ESPAÑOLA DE ENOTURISMO (AEE) (2018): Enoturismo y la RAE. Recuperado el 9 de enero de 2020 de https://www.xn--enoturismodeespaa-uxb.es/web/ text.php?id_section $=1467$

BALDERAS, C.R. (2014): “Características de la demanda del turismo de naturaleza y de aventura en Playa del Carmen”. Teoría y Praxis, Marzo (número especial).

BARBOSA DE SOUSA, B. y DOMINIQUE- FERREIRA, S. (2012): "La innovación de los procesos. Diferenciación en los servicios turísticos", Revista Estudios y Perspectivas en Turismo, vol. 21 (4), pp. 963-976.

BERRY, L.L., CARBONE, L.P. y HAECKEL, S.H. (2002): «Managing the total customer experience», Sloan Management Review, vol. 43 (3), pp. 85-89.

CANALIS, X., DE LA ROSA, J.M., HINOJOSA, V., PORRAS, C., RAMÓN, D. y VARGAS, A. (2016): «Turismo familiar, el rey de la demanda en España”, Revista Hosteltur. Recuperado el 15 de diciembre de 2019 de https://www.hosteltur.com/ edicion-impresa/turismo-familiar.

CHARTERS, S. y ALI-KNIGHT, J. (2000): «Wine tourism a thrist for knowledge?», International Journal of Wine Marketing, vol. 12 (3), pp. 70-80.

CÓRDOBA, E., CASTILLO, N. y CASTILLO, J.L. (2018): “Creatividad e innovación: Motores de desarrollo empresarial”, Lámpsakos, vol. 1 (19), pp. 56-65.

EUROPAPRESS (2019): El impacto económico de los viajes familiares asciende a 18.552 millones en 2019, un 1,3\% más. Recuperado el 15 de diciembre de 2019 de https:// www.europapress.es/turismo/nacional/noticia-impacto-economico-viajes-familiaresasciende-18552-millones-2019-13-mas-20191210135334.html

FEDERACIÓN ESPAÑOLA DE FAMILIAS NUMEROSAS-EXPERTUS TURISMO Y OCIO (2018): V Estudio de Mercado de Pautas de Consumo Turístico de las Familias de España (5). Recuperado el 15 de febrero de 2020 de:http://familiayturismo.com/img/FamiliyTurismo2016/VI\%20Estudio\%20de\%20turismo\%20familiar_ PRESENTACI\%C3\%93NVF.pdf.

FEMENÍA, O. (2011): La imagen de un destino turístico como herramienta de marketing. Málaga, Universidad de Málaga, Grupo EUMEDNET.

FLASH EUROBAROMETER (2016): Preferences of European towards tourism. European Comission. Recuperado el 15 de enero de 2020 de: https://ec.europa. eu/commfrontoffice/publicopinion/index.cfm/Survey/getSurveyDetail/instruments/ FLASH/surveyKy/2065. 
GETZ, D., DOWLING, R., CARLSEN, J. y ANDERSON, D. (1999): «Critical success factors for wine tourism». International Journal of Wine Marketing, vol. 11 (3), pp. 20-43.

GILBERT, D.C. (1992): «Touristic development of a viticultural regions of Spain», Internatioinal Journal of Wine Marketing, vol. 4 (2), pp. 25-32.

GIRINI, L. (2017): «El paisaje como recurso para el desarrollo del enoturismo. El caso de Mendoza, Argentina». Segundo Coloquio Red Uvas Patrimonio Vitivinícola Andino y Turismo Cultural. Universidad Autónoma Juan Misael Saracho, Tarija, Bolivia. Recuperado el 5 de enero de 2020 de: https://www.academia.edu/38238762/El_paisaje_ como_recurso_para_el_desarrollo_del_enoturismo._El_caso_de_Mendoza_Argentina

GONZÁLEZ DURÁN, S. (2013): «Transformaciones urbanas en la margen izquierda del Nervión: turismo, consumo y nuevos paisajes productivos». Revista Vasca de Sociología y Ciencia Política, $\mathrm{n}^{\circ}$ extra 53-54, 2012-2013, págs. 525-533.

HALL, C. M., SHARPLES, L., MITCHELL, R., MACIONIS, N. y CAMBOURNE, B. (2004): Food tourism around the world. London and New York, Ed. Routledge: Taylor and Francis Group.

HERRERO-DIZ, P., RAMOS-SERRANO, M., y NÓ, J. (2016): «Los menores como usuarios creadores en la era digital: del prosumer al creador colaborativo. Revisión teórica 1972-2016», Revista Latina de Comunicación Social, n 71, pp. 1.301-1.322.

LÓPEZ-GUZMÁN, T., RODRÍGUEZ, J., y VIEIRA, A. (2013): «Revisión de la literatura científica sobre enoturismo en España», Cuadernos de Turismo, $\mathrm{n}^{\circ} 32$, pp. 171-188.

MEDINA, F. X. y TRESSERRAS, J. (2008): «Turismo enológico y rutas del vino en Cataluña. Análisis de casos: D.O. Penedès, D.O. Priorat y D.O. Montsant». PASOS. Revista de Turismo y Patrimonio Cultural, vol. 6 (3), pp. 493-509.

MIRANDA, B. y FERNÁNDEZ, R. (2011): «Vino, turismo e innovación: las Rutas del Vino de España, una estrategia integrada de desarrollo rural», Estudios de Economía Aplicada, vol. 29 (1), pp. 129-164.

O'NEILL, M., PALMER, A. y CHARTERS, S. (2002): «Wine production as a service experience. The effects of service quality on wine sales», The Journal of Services Marketing, vol. 16 (4), pp. 342-362.

ORGANIZACIÓN MUNDIAL DEL TURISMO (OMT) (2019): Definiciones de turismo de la OMT Recuperado de https://www.e-unwto.org/doi/pdf/10.18111/9789284420858.

ORGANIZACIÓN MUNDIAL DEL TURISMO (2016): Prototipo de turismo enológico de la OMT. Recuperado el 11 de enero de 2020 de:http://cf.cdn.unwto.org/sites/all/ files/docpdf/prototipoturismoenologicovcortalr_2.pdf

ORGANIZACIÓN MUNDIAL DEL TURISMO (2019): Definiciones de turismo de la OMT. Recuperado de https://www.e-unwto.org/doi/pdf/10.18111/9789284420858

PARENTEAU, A. (2010): «Estado del turismo enológico en Europa», en Libro de Actas del $2^{\circ}$ Congreso Europeo de Turismo industrial. Toledo 2008. pp. 166-170.

RODRÍGUEZ G., GIL, J. y GARCÍA E. (1999): Metodología de la Investigación Cualitativa. Granada, Ed. Aljibe.

RODRÍGUEZ, J., LÓPEZ-GUZMÁN, T. y SÁNCHEZ, S. (2010): «Análisis del desarrollo del enoturismo en España: un estudio de caso». Cultur: Revista de Cultura e Turismo, vol. 4 (2), pp. 51-68. 
SALVAT, J. (2018): «Patrimoni enològic i turismo», Treballs de la Societat Catalana de Geografia, n ${ }^{\circ} 86$, pp. 45-64.

SCHÄNZEL, H. A. y YEOMAN, I. (2015): «Trends in family tourism», Journal of tourism futures, vol. 1 (2), pp. 141-147.

SERRANO, D. (2015): Enoturisme com a fenomen de desenvolupament local al móni a Catalunya. Tesis doctoral. Universitat de Barcelona, Barcelona, España. Recuperado el 21 de enero de 2020 de https://issuu.com/damiaserrano/docs/td_damia_ serrano_v2.

UNWIN, T. (1991): «Wine an the vine». New York. Routledge.

VISIT NAPA VALLEY (2019): Research. 2018. Research Highlights. Recuperado el 21 de diciembre de 2019 de https://www.visitnapavalley.com/about-us/research/. 